\title{
Regional Labor Markets, Network Externalities and Migration: The Case of German Reunification
}

\author{
Harald Uhlig*
}

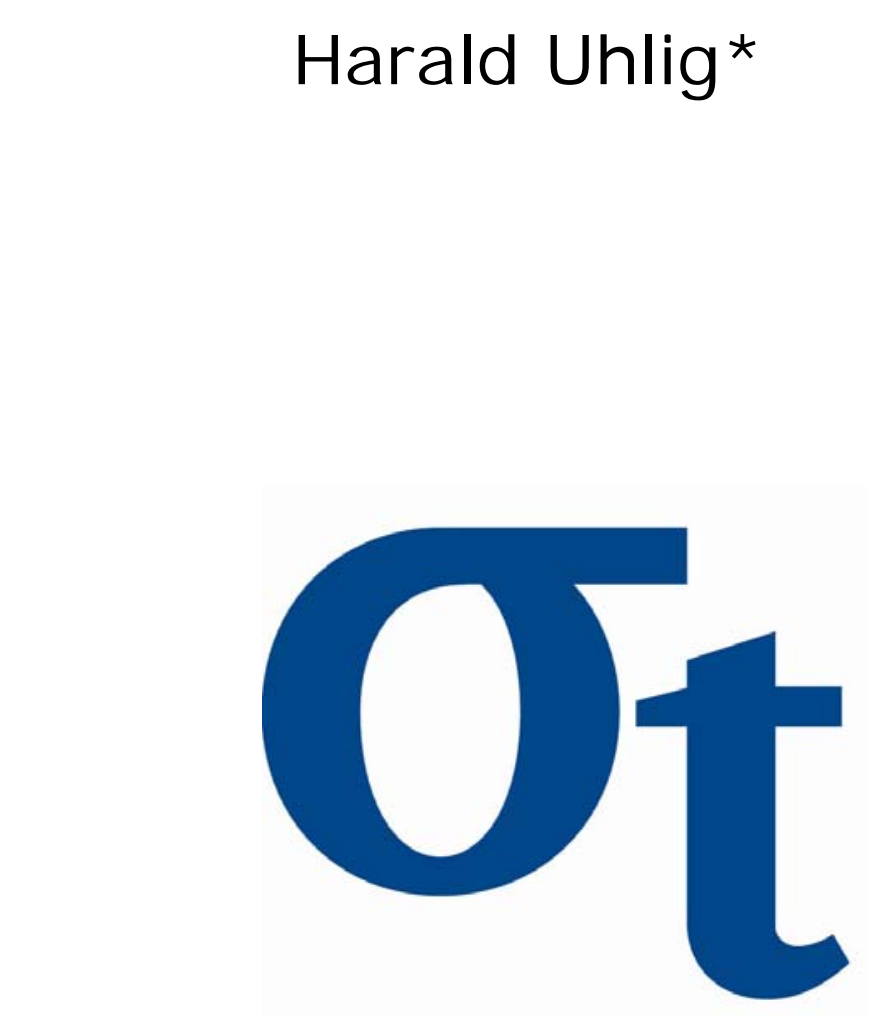

* Humboldt-Universität zu Berlin, Deutsche Bundesbank, CentER and CEPR

$\underline{v}$

U

$\bar{\Upsilon}$

This research was supported by the Deutsche Forschungsgemeinschaft through the SFB 649 "Economic Risk".

http://sfb649. wiwi.hu-berlin.de ISSN 1860-5664 


\title{
Regional labor markets, network externalities and migration: the case of German reunification.*
}

\author{
Harald Uhlig \\ Humboldt Universität zu Berlin \\ Deutsche Bundesbank, CentER and CEPR
}

PRELMINARY

COMMENTS WELCOME

This version: February 6, 2006

*This was written for the 2006 AEA session "German reunification: lessons and legacy".
The original manuscript number and title are MS \#P06074, "Industrial Cores, Waste-
lands and Consequences for Macro Policies: The Case of German Reunification". Ad-
dress: Prof. Harald Uhlig, Humboldt Universität zu Berlin, Wirtschaftswissenschaftliche
Fakultät, Spandauer Str. 1, 10178 Berlin, GERMANY. e-mail: uhlig@wiwi.hu-berlin.de,
phone: +49-30-2093 5626, fax: +49-30-2093 5934, home page http://www.wiwi.hu-
berlin.de/wpol/. This research was supported by the Deutsche Forschungsgemeinschaft
through the SFB 649 "Economic Risk" and by the RTN network MAPMU. I am grateful 


\begin{abstract}
Fifteen years after German reunification, the facts about slow regional convergence have born out the prediction of Barro (1991), except that migration out of East Germany has not slowed down. I document that in particular the 18-29 year old are leaving East Germany, and that the emigration has accelerated in recent years. To understand these patterns, I provide an extension of the standard labor search model by allowing for migration and network externalities. In that theory, two equilibria can result: one with a high networking rate, high average labor productivity, low unemployment and no emigration ("West Germany") and one with a low networking rate, low average labor productivity, high unemployment and a constant rate of emigration ("East Germany"). The model does not imply any obviously sound policies to move from the weakly networked equilibrium to the highly networked equilibrium.
\end{abstract}

Keywords: German reunification, labor market search, network externalities, migration, regional economics

to the participants in the macroeconomics seminar in Toulouse for useful questions and to Olivier Blanchard, Nicola Fuchs-Schündeln, Claudia Buch and Russell Cooper for useful comments. 


\section{Regional labor markets, network externalities and migration: the case of German reunification.}

\section{German reunification: 15 years later.}

Germany was divided into three parts: West Germany, East Germany and Berlin. These three parts have been united together on October 3rd, 1990. Many forecasts regarding the future of Germany have been made then, ranging from the enthusiastic to the dour. 15 years later, it is time to take stock of what has happened since.

Among the most skeptical forecasts, Barro (1991) in a Wall Street Journal op-ed piece warned against too much optimism regarding the speed at which East Germany will catch up with West Germany. He argued that productivity in the East will catch up to West German levels only at "1 1/2 to 2 percentage points per year". He argued that this "will create pressures for the German government to speed up the process. There is, however little ... to suggest that governments can accelerate convergence.". He finally stated, that "the flow of migrants will ... decline over time. The annual number of net migrants will fall to a range of 140,000-230,000 by the year 2001."

Unfortunately, Barro was right for most of his predictions. Average labor productivity in East Germany (without Berlin) for 2001 to 2003 is approximately two thirds the average labor productivity of the West Germany, with the productivity growth rate differential for 1999 to 2003 at $1.6 \%$, in line with or only slightly better than Barro's prediction. Fiscal transfers into East Germany have been massive, for a total transfer of nearly one trillion 
Euros from West to East Germany from 1991 to 2003, averaging close to 37\% of East German GDP throughout. These transfers may have improved the lifes of East Germans, but they do not seem to have accelerated convergence. If anything, the anemic growth of Germany during the last 15 years may be due to these transfers, see Canova and Ravn (2000) or Sinn (2002).

The average net migration rate for 2001-2003 of approximately 73 thousand (subtracting an average inflow of 134 thousand from an average outflow of 207 thousand) is close to the average of the preceeding ten years: only the gross flows are as high as Barro predicted. It seems likely that the large fiscal transfers acted as a "bribe" to the East Germans to mostly stay where they were, keeping them from competing against West Germans for jobs at lower wages, or to lure West Germans to come. But the more discomforting fact here is that migration has not slowed down, which makes matters even worse than Barro predicted. While the population in West Germany is growing, it is shrinking in East Germany. The differential of the population growth rates (excluding Berlin) is 1\%, whether one calculates it for 1991 to 2004 or just for the last five of these years.

To investigate the issue of inner-German migration further, I have examined regional data available from the Statistisches Bundesamt. A more detailed presentation of this data as well as the model below is in Uhlig (2006). Further investigations of East-West-German migration and commuting is presented in Hunt (2006) and Izem and Fuchs-Schündeln (2006).

For each district or "Kreis" in Germany, each year from 1995 to 2003 and several age groups, data is available on reallocations crossing its border. For 2003, detailed population data is available. Whenever the district name contained the word "Stadt", the German word for city, I have categorized it as a city (or a "large city", if the population exceeded 100000), otherwise as 
countryside, although much of it presumably also serves as extended suburbs. The population splits 80-20 between West and East, and 28\%, 3\% and 68\% across large cities, small cities and countryside.

While all groups tend to leave East Germany, except for the above-50-year olds, the numbers are particularly large for the 18-29 year old, i.e. the future work force, see figure 1. There is an exodus of these people in particular from small cities and rural East Germany, in contrast to the pattern in West Germany. On average for the last five years in the data, $1.9 \%$ of the $18-29$ year old left East Germany excluding Berlin for Berlin and West Germany, and their migration appears to accelerate rather than slow down. This is not compensated for by middle-age families with young children. The 30-49 year old are also leaving on net, albeit at a slower rate. Additionally, the birth rates per female in East Germany from 1991 to 2004 is only about two thirds of the (already low) birth rate in West Germany, and only slowly catching up. It appears that East Germany is slowly but surely aging and dying, except for a few vibrant core areas and big cities.

Furthermore, the slow convergence of the East to the West should perhaps surprise more than usual. The disparity between East and West Germany is not the result of many years of a gradual drifting-apart - as is the case for the regions analyzed by Barro and Sala-i-Martin (1995). Rather, here are two parts of the same country, one of which has been held back artifically during the postwar years. This is similar to the distinction between choosing or being assigned to a civil service job, exploited by Fuchs-Schündeln and Schündeln (2005) to measure risk-aversion. What is therefore needed is a theory consistent with the following stylized facts. There is persistent migration from East to West Germany, in particular by the age group 18 to 29 . Unemployment in East Germany is higher than in West Germany. Wages 
are lower in East Germany. Average labor productivity is lower in East Germany. The welfare system provides for comparable benefits in East and West Germany to short- and long-term unemployed workers. There have been and continue to be sizeable fiscal transfers from West to East Germany. Legal and educational differences between East and West Germany are minor.

\section{A model of regional labor markets, network externalities and migration.}

Surely, market distortions and policy interference in East Germany have been big, see Snower and Merkl (2006) and adjustment costs are large, see Burda (2006). But should we be confident that East Germany would recover quickly, if all these policy distortions were to be removed? The model in this section provides a simple framework to show that this may not be so. It shows that one region (East Germany) can have higher unemployment, lower productivity and persistent outward migration compared to another region (West Germany) and without any convergence taking place, despite the absence of policy distortions or costs to moving factors of production (while the latter is the main cause of the slowdown of convergence in Burda, 2006). Workers also do not suddenly become more skilled by moving from East to West. Rather, I argue, that agglomeration effects play a key role, see also Fujita, Krugman and Venables (1999) and Cooper (1999).

A standard labor search model would predict that the initially higher unemployment in the East should attract relatively more vacancy creation than in the West. Migration would provide for an additional valve. Something more is needed. I therefore extend the standard labor search model to allow 
for migration as well as network externalities of production. I closely follow the notation and exposition of Rogerson, Shimer and Wright (2005), section 4. I will only study steady-state equilibria with constant shares of each type of worker in the population of the region, and therefore leave away time subscripts, unless necessary. The model is described as a partial equilibrium in the sense that the destination region for migration is not modelled explicitly, but it will be obvious at the end how this could be done.

For the network externalities, consider a match of a worker and a firm. In isolation, production is assumed to be $y_{m}$ ( $\mathrm{m}$ for "match"). I assume that it is beneficial for this pair to join a network of enterprises and specialize on some specific task. Thus, as part of a network, the production by this pair is now assumed to be $y_{n}>y_{m}$ ( $n$ for "network"). Joining a network is probabilistic. I assume that this probability depends on the ratio of non-networked firmworker-pairs $m_{t}$ to networked firm-worker pairs $n_{t}$ : this turns out to make the model fairly tractable. Thus, let $\nu=\nu\left(m_{t} / n_{t}\right)$ be the instantaneous probability for a non-networked firm-worker match to become part of some network of firms. Division of labor is beneficial to all: so, the larger the networks, the better. There is no rivalry in joining a network. Furthermore, the more networks are already present, the larger shall be the chance of an unmatched firm to join one. I therefore assume that $\nu(\cdot)$ is decreasing. For simplicity, I assume that $\nu=\nu_{h}>0$ for $m_{t} / n_{t} \leq \psi$ and $0 \leq \nu=\nu_{l}<\nu_{h}$ for $m_{t} / n_{t}>\psi$ and some value $\psi>0$, satisfying

$$
\nu_{l} \psi<\lambda<\nu_{h} \psi
$$

where $\lambda$ is the exogenous job separation rate for (networked) firm-worker matches. I shall write $\nu$, keeping in mind, that this can take one of the two values. I will calculate the equilibrium for a "guess" for $\nu$ and then determine 
$\nu$ with the equilibrium ratio of $m_{t}$ to $n_{t}$. The emergence and importance of clusters in East Germany has recently been studied and documented in Rosenfeld et al. (2004).

For the migration part, I assume that agents have the option of moving from the region under consideration to some other outside region. Agents experience a disutility $\kappa>0$ from moving, expressed in wage-equivalent units. I assume that a new disutility level $\kappa^{\prime}$ is drawn iid from some distribution $F(\kappa)$ at the rate $\phi$. Let $U$ be the value to an unemployed worker in the region under consideration ("East Germany") and let $\bar{U}$ be the value to an unemployed worker in the destination region ("West Germany"). Upon receiving a new draw of the disutility $\kappa$, the worker will move, iff $U \leq \bar{U}-\kappa$. Let $\kappa^{*}$ be value, for which equality is achieved. I shall ignore the immigration term, and approximate it per $\iota=0$ for simplicity.

The other features are standard and are taken from Rogerson, Shimer and Wright (2005), section 4, modified to allow for non-networked as well as networked matches. I assume that workers can be unemployed, or produce in a match. While unemployed, workers receive benefits $b$. Firms can post vacancies at a flow cost $r k$ per unit of time of posting the vacancy. There is free entry to posting vacancies. Let $u$ be the mass of unemployed workers and $v$ the mass of vacancies. Matching between vacant positions and workers happens according to a constant-returns-to-scale matching function. I write $\alpha_{w}=\alpha_{w}(v / u)$ for the rate at which unemployed workers find a job, and $\alpha_{e}=\alpha_{e}(v / u)=\alpha_{w}(v / u) /(v / u)$ be the rate, at which vacancies are filled, with $\alpha_{w}(\cdot)$ increasing and $\alpha_{e}(\cdot)$ decreasing in their argument.

In a match, continuous bargaining assures that the worker receives a share $0<\theta<1$ of the joint remaining surplus from production, which I denote with $S_{m}$ for matched, but not yet networked firm-worker pairs, and $S_{n}$ for 
networked firm-worker pairs. I assume that there is an exogenous separation rate $\lambda$, regardless of whether the match is networked or not. I assume that workers and firms discount the future at rate $r$.

\subsection{Analysis and Results}

The value of being unemployed is given by

$$
r U=\tilde{b}+\alpha_{w} \theta S_{m}
$$

where

$$
\tilde{b}=b+\phi \int_{0}^{\kappa^{*}} F(\kappa) d \kappa
$$

increases the standard unemployment compensation $b$ to $\tilde{b}$ by the "option value" of moving to the outside region. It depends on $U$ via the migration threshold $\kappa^{*}=\bar{U}-U$.

As in equation (43) of Rogerson, Shimer and Wright (2005), it can be shown that the firm and worker matching rates $\alpha_{e}$ and $\alpha_{w}$ satisfy

$$
\frac{r+\lambda+\alpha_{w} \theta}{(1-\theta) \alpha_{e}}=\frac{\tilde{y}-\tilde{b}}{k}
$$

where

$$
\tilde{y}=\tilde{y}(\nu)=y_{m}+\frac{\nu}{r+\lambda+\nu}\left(y_{n}-y_{m}\right)
$$

is an average of the labor productivities. Given $\nu$, this equation amounts to a fixed point problem in $\kappa^{*}$. One can show that there is a unique fixed point as a continuous function of $\phi$ for $\phi$ near zero.

Equation (3) shows, that a lower networking rate $\nu$ and a larger migration rate $\phi F\left(\kappa^{*}\right)$ both have the effect of discouraging job creation. In particular and counter-intuitively, the option to migrate increases rather than decreases 
unemployment. This is so because the option to migrate makes workers more demanding, since they additionally have the alternative to wait for a good opportunity of moving.

For moderate parameters, only unemployed workers find it beneficial to move. The population then decreases forever at the constant rate $\frac{\dot{\pi}_{t}}{\pi_{t}}=$ $-\phi F\left(\kappa_{t}^{*}\right) \tilde{u}$, where $\tilde{u}$ is the (constant-in-the-steady-state) unemployment rate $\tilde{u}=u / \pi$. The equilibrium ratio of $m_{t}$ to $n_{t}$ needs to satisfy

$$
\nu \frac{m_{t}}{n_{t}}=\left(\lambda-\phi F\left(\kappa^{*}\right) \tilde{u}\right)
$$

With (1), the calculated equilibrium is consistent with both $\nu=\nu_{l}$ and $\nu=\nu_{h}$ and the step function assumed above for $\nu=\nu\left(m_{t} / n_{t}\right)$, provided $\phi$ or $F\left(\kappa^{*}\right)$ is sufficiently small.

There are therefore two equilibria. The "highly networked" equilibrium, which I call W ("West Germany"), is the equilibrium, in which $\nu=\nu_{h}$, unemployment is low, and average labor productivity $\tilde{y}(\nu)$ is high. In a full general equilibrium, this equilibrium ought to characterize the destination region, thus fixing $\bar{U}$. The "weakly networked equilibrium", which I call E ("East Germany"), features $\nu=\nu_{l}$, high unemployment and persistent emigration. The two equilibria balance two offsetting forces. The relatively higher unemployment in equilibrium E attracts more vacancy creation than in equilibrium W. However, the surplus from production is lower in the $\mathrm{E}$ equilibrium, due to the lower networking rate, discouraging vacancy creation. Interestingly, for large enough values of $\phi$, the equilibrium $\mathrm{E}$ disappears. Likewise, the highly networked equilibrium $W$ may disappear with a high rate of immigration due to overloading the capacity of existing networks to integrate new members. 


\section{References}

[1] Barro, Robert J. (1991, May 3rd), "Eastern Germany's long haul," in The Wall Street Journal, Dow Jones and Company.

[2] Barro, Robert J. and Xavier Sala-i-Martin (1995), Economic Growth, New York: McGraw-Hill.

[3] Burda, Michael (2006), "What kind of shock was it? Regional integration of Eastern Germany after unification," American Economic Review, Papers and Proceedings, this issue.

[4] Canova, Fabio Canova and Morten Ravn (2000), "The Macroeconomic Effects of German Unification: Real Adjustments and the Welfare State," Review of Economic Dynamics, Academic Press for the Society for Economic Dynamics, vol. 3(3), pages 423-460.

[5] Cooper, Russell W. (1999), Coordination Games, Cambridge University Press, Cambridge, UK.

[6] Fuchs-Schündeln, Nicola and Izem, Rima (2006), "What Causes the Low Labor Productivity in East Germany? A Spatial Analysis.", draft, Harvard University.

[7] Fuchs-Schündeln, Nicola and Schündeln, Matthias, (2005), "Precautionary Savings and Self-Selection - Evidence from the German Reunification "Experiment" ", Quarterly Journal of Economics, 120(3), 1085-1120.

[8] Hunt, Jennifer (2006), "Staunching Emigration from East Germany: Age and the Determinants of Migration," Journal of the European Economic Association, forthcoming. 
[9] Fujita, Masahisa, Paul Krugman and Anthony J. Venables (1999), The Spatial Economy: Cities, Regions and International Trade. MIT Press.

[10] Rogerson, Richard, Robert Shimer and Randall Wright (2005), "SearchTheoretic Models of the Lsbor Market: a survey," draft, University of Pennsylvania.

[11] Rosenfeld, Martin et al. (October 2004), Innovative Kompetenzfelder, Produktionsnetzwerke und Branchenschwerpunkte der ostdeutschen Wirtschaft. Endbericht, a study at the Institute für Wirtschaftsforschung Halle, IWH.

[12] Sinn, Gerlinde and Sinn, Hans-Werner (1993), Kaltstart. Volkswirtschaftliche Aspekte der deutschen Vereinigung., 3rd edition, Munich 1993.

[13] Sinn, Hans-Werner (2002), "Germany's Economic Unification: An Assessment after Ten Years," Review of International Economics, 10(1), 113-128.

[14] Snower, Dennis J. and Merkl, Christian (2006), "The Caring Hand that Cripples: The East German Labor Market after Reunification," American Economic Review, Papers and Proceedings, this issue.

[15] Uhlig, Harald (2006), " Regional labor markets, network externalities and migration: the case of German reunification.", Sonderforschungsbereich 649 Discussion Paper 2006-004, Humboldt Universität zu Berlin. 
TITLE: East

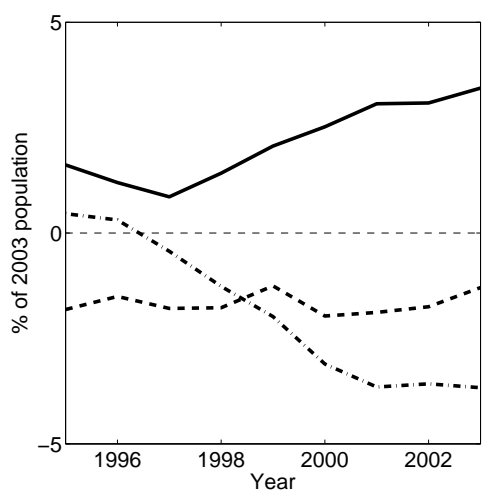

West

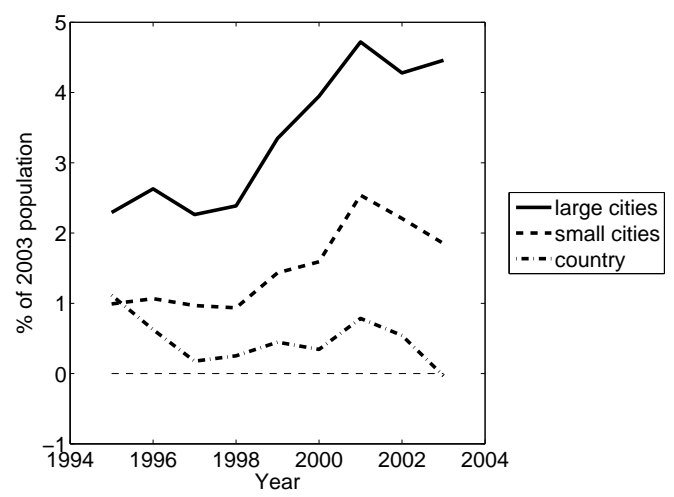

Figure 1: CAPTION:Migration patterns of 18-29 year olds in percent of the 2003 population. The data includes movements from and to Germany. 


\section{Technical Appendix}

The technical appendix is essentially a longer version of the shorter, main paper, providing additional detail and discussion.

\section{A German reunification: 15 years later.}

Germany was divided into three parts: West Germany, East Germany and Berlin. These three parts have been united together on October 3rd, 1990. 15 years later, it is time to take stock of what has happened since. Fiscal transfers into East Germany have been massive. According to Busch (2002) for 1991 to 1999, own calculations for 2003, and a linear interpolation for 2000 to 2002, a total net transfer of 940 billion Euros has been paid from West to East Germany for the time span from 1991 to 2003. Figure 3 shows that the transfers have been more than one third of East German GDP on average: indeed, the absolute amount of the transfers has been steadily rising or barely falling for most of these years. While approximately $20 \%$ of the (gross) transfers have been used to pay for subsidies to firms as well as to building infrastructure, approximately 50\% have taken the form of direct transfers for socio-political reasons. Due to the East-West transfers, the perresident fiscal budget of the East German Bundesländer is approximately $15 \%$ higher than in the West. These transfers have been financed mostly with an increase in debt. Additionally, a "solidarity tax" has raised a total of nearly 90 billion Euros from 1991 to 2000.

Despite (or, possibly, because) of these transfers, convergence of conditions in East Germany to those in the West have been slow. Indeed, Canova and Ravn (2000) have shown, that reunification is tantamount to a mass 
migration of low-skilled agents holding no capital into a foreign country. Using an extension of standard neoclassical growth theory, they show how this should have let to an investment boom in the absence of a welfare state, but a prolonged recession in its presence. Thus, the anemic growth in Germany and many of the reunification problems may possibly find their cause rather than their remedy in these massive transfers to the East. This also echoes the warning of Sinn and Sinn (1993), reiterated in Sinn (2002), against raising the wages in East Germany too quickly to West German levels.

The slow rate of convergence between regions is another matter, however. Germany is not unusual in this respect. For disparate regions in a country, the slow convergence process has been documented e.g. by Barro and Salai-Martin in a series of papers, summarized in their book (1995). Based on this research, Barro (1991) warned against too much optimism regarding the speed at which East Germany will catch up with West Germany in a Wall Street Journal op-ed piece. He stated then that "there are substantial variations in estimates of East German productivity in 1990; a reasonable range is from one-third to one-half the West German figure. An extrapolation of the U.S. experience to the eastern regions of unified Germany implies that per-capita growth in the East would be initially $11 / 2$ to 2 percentage points per year higher than in the West. This growth advantage ... means that it will take about 15 years to eliminate one-half of the gap ... If so, the East would eventually catch up to the West, but in a couple of generations rather than a couple of years or a couple of decades." Barro's forecast turns out to be close to the current facts. 10 to 15 years after reunification, average labor productivity in East Germany (without Berlin) for 2001 to 2003 is at approximately two thirds the average labor productivity of West Germany (without Berlin), and therefore pretty much exactly where Barro predicted 
it would be. Likewise, the productivity growth rate differential between East Germany (without Berlin) and West Germany (without Berlin) for 1999 to 2003 is $1.6 \%$, in line with Barro's prediction.

The prediction in the Wall Street Journal appears to be a slight misprint, however. Given a convergence rate of $2 \%$ annually, one finds that $\exp (-.02 n)=.75$ is solved by $n=14.4$ and $\exp (-.02 n)=.5$ is solved by $n=34.7$. I.e., in 15 years, only a quarter of the productivity gap should have been eliminated, and it would take 35 years to eliminate half of it. This indeed is the (corrected) statement in Barro (1996), p.14, with an update of the analysis in Barro (2002). Compared to that calculation, productivity convergence appears to be faster, at first blush. Figure 2 provides greater detail, using the numbers from Burda (2006). Productivity convergence appears to have been fast from 1991 to 1993, so the prediction based on the 1991 numbers is far from the facts. Applying the prediction on the basis of the numbers for 1993, however, works surprisingly well. Whether the fast productivity growth in 1993 is due to mismeasurement prior to that date, whether this is due to low-productivity enterprises having simply been shut down, or whether there really has been a rather dramatic catchup in productivity in 1991 to 1993 might be an interesting subject of further research. My guess is that the former two explanations are far more likely than the latter. I conclude from this, tentatively, that the productivity convergence prediction by Barro was right, subject to a productivity jump between 1991 and 1993, probably due to some data revision or firm-closing.

His other prediction - the slowdown of migration - did not (yet) pan out, though, see figure 4. Barro stated that "the flow of migrants will ... decline over time for two reasons: first, the East's per-capita income will rise, if slowly, relative to the West's; and second, cumulated migration will 
cause the West's population density to rise relative to the East's, thereby making the West relatively less attractive. The combination of these two forces implies that the annual number of net migrants will fall to a range of 140,000-230,000 by the year 2001; the projected cumulative number of migrants for the period 1991-2001 is 1.7 to 2.8 million.". Migration from East to West Germany was never quite as high: the total was approximately 0.7 million from 1991-2001, and the average migration rate for 2001-2003 of approximately 70 thousand is close to the average of the preceeding ten years. One interpretation is that East Germans were initially "bribed" with the huge transfers to stay where they are, and that we now witness residual pent-up migration, as these transfers are scheduled to be gradually phased out. Another possibility is that migration from East to West Germany will continue to persist, turning East Germany into a deserted wasteland, except for a few industrial core regions. Since these migratory pattern differ from those predicted by Barro, I shall investigate them more closely in section B. I find that migration is particularly strong for the age group of 18 to 29 year olds, and it is particularly strong from the country side and small cities, and much stronger than the corresponding pattern for West Germany. It appears that East Germany is slowly but surely gentrifying and dying.

In light of the analyses of Barro and Sala-i-Martin, one may be tempted to explain this pattern within the context of standard endogenous growth theories, in line with the usual explanation of slow regional convergence.

But something is amiss. The disparity between East and West Germany is not the result of many years of a gradual drifting-apart - as it is the case for the disparate regions in West Germany, the United States or Japan, which Barro and Sala-i-Martin have analyzed. Rather, here are two parts of the same country, one of which has been held back artifically during the postwar 
years ${ }^{1}$.

The regions are homogenous in many ways - the same climate, the same legal system, the same language and a similar level of general education. Technologies and blueprints can easily be transferred, capital can easily be moved. The slow rate of convergence of East to West Germany strikes me as more surprising than usual. In sum, what is needed is a theory consistent with the following stylized facts:

1. There is persistent migration from East to West Germany, in particular by the age group 18 to 29 .

2. Unemployment in East Germany is higher than in West Germany.

3. Wages are lower in East Germany.

4. Average labor productivity is lower in East Germany.

5. The welfare system provides for comparable benefits in East and West Germany to short- and long-term unemployed workers.

6. There have been and continue to be sizeable fiscal transfers from West to East Germany.

7. East and West Germany operate subject to the same federal law. Regional differences in the legal system and regulations are minor.

8. Regional differences in the educational system are minor.

\footnotetext{
${ }^{1}$ This is similar to the distinction between risk-averse agents self-selecting into civil service job in West Germany and former East Germans being given a civil service job in East Germany, a distinction exploited by Fuchs-Schündeln and Schündeln (2005) to calculate the impact of risk aversion on occupational choice.
} 
9. Real estate is cheaper in East Germany.

It certainly is the case that the job-specific skills and training of the workers in the East were not suitable to the new capitalist world of the West. However, the current generation of 18 to 29 year olds, which are leaving East Germany in large numbers, were small children or at most teenagers by the time German reunification happened: their education and job-specific training should be on par with that of their age-compatriots in the West. It is conceivable, that the only way for them to receive apprenticeship training is to move to westwards - but then again, why do firms not move eastwards, exploiting the cost advantage of lower real estate prices, lower wages and compensation?

What I seek is a theory of two otherwise identical regions, but where one region has higher unemployment and lower average productivity than the other, and where there is continuous, unceasing migration from the lowproductivity to the high-productivity region. A standard labor search model would predict that the initially higher unemployment in the East should attract relatively more vacancy creation than in the West. Extending such a model to a two-region world with migration between them would add another valve for releasing the pressure of inequality and would eventually simply result in an equalization of the conditions in both regions. Furthermore, a reasonable parameterization would imply that this convergence happens quickly. Something more is required to make the differences persist.

Two devices come to mind. The first is costly signalling, see e.g. Spence (1973). High-quality young workers may wish to signal their high quality by the costly move to the West, whereas the low-quality young workers remain behind. I find it a bit hard to believe, however, that the informational asymmetries between firms and prospective employers could be so massive. 
The second device is some kind of complementarity. One possibility is a regional sorting according to the quality of its inhabitants, as in Kremer (1993). A second possibility is a network externality between producing firms. While firms can produce in isolation, selling their products on some anonymous market, they can often be more productive by specialization as part of a larger network of firms. A hotel can outsource many of its services like cleaning or repairs, provided such services are available from specialized firms close by. A machine or car manufacturer may outsource the production of specialized parts.

In section C, I provide such a model, extending the standard labor search model to allow for emigration as well as network externalities of production. The model has two equilibria. The "highly networked" equilibrium is the equilibrium, in which unemployment is low and average labor productivity is high, characterizing the destination region ("West Germany", "vibrant city", "industrial core") for migrants. The "weakly networked equilibrium" by contrast is characterized by high unemployment and persistent emigration. The possibility to emigrate weakens job creation further, as the option value of emigration acts like an added unemployment benefit. One may want to think of this equilibrium as characterizing "East Germany". Emigration in this model never stops, eventually turning a dying region into a wasteland.

\section{B Facts on Inner-German migration.}

The general pattern of migration from East to West Germany since 1991 is shown in figure 4. The data counts East Berlin as part of East Germany before 2000, and all of Berlin from 2000 onwards. What is remarkable about this picture is that migration from East to West Germany has not come 
to rest after the initial post-unification wave. Rather, and since 1997, net emigration from East Germany has increased again. Slowly, but gradually, East Germany is shrinking in population, compared to the West.

Further investigations of East-West-German migration and commuting is presented in Hunt (2006) and Izem and Fuchs-Schündeln (2006). Here, in order to examine the issue of inner-German migration further, I have examined regional data available from the "Statistische Ämter des Bundes und der Länder", available per https://www.regionalstatistik.de/genesis/online/logon. Germany is divided into 439 "Kreise" or regions, including the city states Berlin and Hamburg. For each Kreis, each year from 1995 to 2003 and several age groups, data is available on emigration and immigration, i.e., reallocations crossing the border of the Kreis. Furthermore, for 2003, detailed population data is available. The data lists the names for each Kreis. Whenever it contained the word "Stadt", the German word for city, I have categorized the Kreis as a city, otherwise as countryside. Obviously, the "countryside" should properly be regarded also as serving as an extended suburb. Given modern possibilities for commuting, the distinction is blurred, certainly in a densely populated country such as Germany. Following the usual convention, I have categorized cities with a total population in 2003 of more than 100.000 as a large city and below that as a small city. The distribution across the various categories can be seen in table 1 .

Figure 5 shows the distribution of the city sizes in East and West, plotting the log of the fraction of cities above a certain size versus the log of that size. As is well-known as Zipf's law, one often obtains a fairly straight line, see e.g. Krugman (1996) or Gabaix and Ioannides (2004): the same is true here.

Next, I calculate the migration rates of subpopulations within each of these categories and for various age groups, expressed in percent of the 2003 


\begin{tabular}{|c|c|c|c|}
\hline & All & East & West \\
\hline \multicolumn{4}{|c|}{ Total Population: } \\
\hline Number of "Kreise" & 439 & 113 & 326 \\
\hline popul. in $\%$ of total & 100 & 20 & 80 \\
\hline \multicolumn{4}{|c|}{ Large Cities: } \\
\hline \multirow{2}{*}{$\begin{array}{l}\text { Number of "Kreise" } \\
\text { popul. in \% of region }\end{array}$} & 70 & 12 & 58 \\
\hline & 28 & 35 & 27 \\
\hline \multicolumn{4}{|c|}{... without Berlin, Hamburg: } \\
\hline \multirow{2}{*}{$\begin{array}{l}\text { Number of "Kreise" } \\
\text { popul. in \% of region }\end{array}$} & 68 & 11 & 57 \\
\hline & 22 & 15 & 24 \\
\hline \multicolumn{4}{|c|}{ Small Cities: } \\
\hline \multirow{2}{*}{$\begin{array}{l}\text { Number of "Kreise" } \\
\text { popul. in \% of region }\end{array}$} & 46 & 15 & 31 \\
\hline & 3 & 6 & 3 \\
\hline \multicolumn{4}{|c|}{ Countryside: } \\
\hline \multirow{2}{*}{$\begin{array}{l}\text { Number of "Kreise" } \\
\text { popul. in \% of region }\end{array}$} & 323 & 86 & 237 \\
\hline & 68 & 59 & 71 \\
\hline
\end{tabular}

Table 1: Distribution of the population in Germany. 
population. Figure 8 shows a key pattern: the future work force of East Germany, i.e., the population aged 18 to 29 years, is leaving East Germany in large numbers. While there is considerable "churning", i.e., while gross flows are considerably larger than net flows, there is little doubt that gradually and persistently, East Germany is shrinking in the relevant working-age population. This is also corroborated by figure 6: essentially, only people above age 50 stay in East Germany, all others gradually leave. Note also, that the migration pattern of people below 17 is nearly identical to the migration pattern of the group aged 30-49, since the former are the children of the latter. I therefore do not plot this age group in the other figures.

In figure 6, migrants crossing the German border are included. This makes a substantial difference, as a visual comparison to 4 already shows. While the latter shows persistent emigration from East to West Germany, 6 seems to indicate that there was net positive immigration until about 1997. Thus, figure 7 shows only the numbers for inner-German migration. The numbers now look bleaker, as it excludes a fairly large number of immigrants to East Germany from foreign countries. Since both types of numbers shed different light on the phenomenon, I included both throughout. For example, figure 9 is the companion figure to figure 8 .

The fact that East Germans are leaving East Germany is particularly true for the country side. Figure 10 compares the migration patterns for various regions and age groups in East and West Germany. Figure 11 concentrates on inner-German migrants, i.e., excludes migration crossing the German border. While the country side provides a stable or even growing environment in West Germany, there is an exodus of young people in rural East Germany. Cities are generally attractive to young people, but more so in the West, while people above 30 and their young children (not shown) leave East German 
city at a faster rate than in the West. Figure 12 and figure 13 (for only inner-German migration) focusses on the migration pattern of people at age 18 to 29 , showing both the rates (in percent of the 2003 population) as well as the cummulative effect. The cummulative effect needs to be taken with the caveat, that people age, i.e., the group of 18-29 year olds is replenished by young children, as they age, etc.. Nonetheless, the implied changes in the population of East Germany, in particular, rural East Germany, and the generational composition of this population is shifting dramatically and continues to do so, 15 years after reunification.

\section{A model of labor search, migration and network externalities: Details.}

\section{C.1 The model}

To shed light on these phenomena, I consider an extension of the standard labor search model. Surely, market distortions and policy interference in East Germany have been big, see Snower and Merkl (2006) and adjustment costs are large, see Burda (2006). But should we be confident that East Germany would recover quickly, if all these policy distortions were to be removed? The model in this section provides a simple framework to show that this may not be so. It shows that one region (East Germany) can have higher unemployment, lower productivity and persistent outward migration compared to another region (West Germany) and without any convergence taking place, despite the absence of policy distortions or costs to moving factors of production (while the latter is the main cause of the slowdown of convergence in Burda, 2006). Workers also do not suddenly become more skilled by moving 
from East to West. Rather, I argue, that agglomeration effects play a key role, see also Fujita, Krugman and Venables (1999), Krugman (1996) and Cooper (1999).

A standard labor search model would predict that the initially higher unemployment in the East should attract relatively more vacancy creation than in the West. Migration would provide for an additional valve. Something more is needed. I therefore extend the standard labor search model to allow for migration as well as network externalities of production. I closely follow the notation and exposition of Rogerson, Shimer and Wright (2005), section 4. I will only study steady-state equilibria with constant shares of each type of worker in the population of the region, and therefore leave away time subscripts, unless necessary. I need to be careful in formulating the assumptions in order for a steady state to exist. The model is described as a partial equilibrium in the sense that the destination region for migration is not modelled explicitly, but it will be obvious at the end how this could be done.

For the network externalities, consider a match of a worker and a firm. In isolation, production is assumed to be $y_{m}$ ( $\mathrm{m}$ for "match"). I assume that it is beneficial for this pair to join a network of enterprises and specialize on some specific task. Thus, as part of a network, the production by this pair is now assumed to be $y_{n}>y_{m}$ ( $n$ for "network"). Joining a network is probabilistic. I assume that this probability depends on the ratio of non-networked firmworker-pairs $m_{t}$ to networked firm-worker pairs $n_{t}$ : this turns out to make the model fairly tractable. Thus, let $\nu=\nu\left(m_{t} / n_{t}\right)$ be the instantaneous probability for a non-networked firm-worker match to become part of some network of firms. Division of labor is beneficial to all: so, the larger the networks, the better. There is no rivalry in joining a network. Furthermore, 
the more networks are already present, the larger shall be the chance of an unmatched firm to join one. I therefore assume that $\nu(\cdot)$ is decreasing. For simplicity, I assume that $\nu=\nu_{h}>0$ for $m_{t} / n_{t} \leq \psi$ and $0 \leq \nu=\nu_{l}<\nu_{h}$ for $m_{t} / n_{t}>\psi$ and some value $\psi>0$, satisfying

$$
\nu_{l} \psi<\lambda<\nu_{h} \psi
$$

where $\lambda$ is the exogenous job separation rate for (networked) firm-worker matches. I shall write $\nu$, keeping in mind, that this can take one of the two values. I will calculate the equilibrium for a "guess" for $\nu$ and then determine $\nu$ with the equilibrium ratio of $m_{t}$ to $n_{t}$.

For the migration part, I assume that agents have the option of moving from the region under consideration to some other outside region. Agents experience a disutility $\kappa>0$ from moving, expressed in wage-equivalent units. I assume that with some instantaneous probability $\phi$, a new disutility level $\kappa^{\prime}$ is drawn iid from some distribution $F(\kappa)$. Let $U$ be the value to an unemployed worker in the region under consideration ("East Germany") and let $\bar{U}$ be the value to an unemployed worker in the destination region ("West Germany"). Upon receiving a new draw of the disutility $\kappa$, the worker will move, iff $U \leq \bar{U}-\kappa$. Let $\kappa^{*}$ be value, for which equality is achieved. This modelling assumption can be seen as a rather stylized way of capturing the fact that young people in practice find it easier to move for a variety of reasons - family considerations, social networks, habits, etc. - than older people. With this interpretation, the probability $\phi$ is the probability of "rebirth", with an age ( parameterized as moving disutility) randomly drawn from the population distribution. The alternative would be to model a labor search market with life-cycle considerations which gets elaborate fairly quickly. I let $\iota$ be the rate of immigration into the region. For the West, $\iota$ should be 
thought of as positive. Since migration is from East to West Germany, and since West Germany is about three times as large as East Germany, I shall ignore the immigration term, and use the approximation $\iota=0$ for simplicity.

The other features are standard and are taken from Rogerson, Shimer and Wright (2005), section 4, modified to allow for non-networked as well as networked matches. I assume that workers can be unemployed, or produce in a match. While unemployed, workers receive benefits $b$. Firms can post vacancies at a flow cost $r k$ per unit of time of posting the vacancy. There is free entry to posting vacancies. Let $u$ be the mass of unemployed workers and $v$ the mass of vacancies. Matching between vacant positions and workers happens according to a constant-returns-to-scale matching function. I write $\alpha_{w}=\alpha_{w}(v / u)$ for the rate at which unemployed workers find a job, and $\alpha_{e}=\alpha_{e}(v / u)=\alpha_{w}(v / u) /(v / u)$ be the rate, at which vacancies are filled, with $\alpha_{w}(\cdot)$ increasing and $\alpha_{e}(\cdot)$ decreasing in their argument.

In a match, continuous bargaining assures that the worker receives a share $0<\theta<1$ of the joint remaining surplus from production, which I denote with $S_{n}$ for matched, but not yet networked firm-worker pairs, and $S_{n}$ for networked firm-worker pairs. I assume that there is an exogenous separation rate $\lambda$, regardless of whether the match is networked or not. I assume that workers and firms discount the future at rate $r$.

\section{C.2 Analysis and Results}

The value of being unemployed is given by

$$
r U=b+\phi \chi\left(\kappa^{*}\right)+\alpha_{w} \theta S_{m}
$$

where

$$
\chi\left(\kappa^{*}\right)=F\left(\kappa^{*}\right)\left(\bar{U}-U-E\left[\kappa \mid \kappa \leq \kappa^{*}\right]\right)
$$




$$
=\int_{0}^{\kappa^{*}} F(\kappa) d \kappa
$$

is the "option value" of moving to the outside region. It depends on $U$ via the cutoff-level $\kappa^{*}=\bar{U}-U$. Equation (7) shows that the possibility of moving to another region is tantamount to increasing the benefit level $b$ to

$$
\tilde{b}=b+\phi \chi\left(\kappa^{*}\right)
$$

since the option value of moving increases the value of being unemployed ${ }^{2}$.

The two equations for the surplus $S_{m}$ and $S_{n}$ are given by

$$
\begin{aligned}
(r+\lambda+\nu) S_{m} & =y_{m}-r U+\nu S_{n} \\
(r+\lambda) S_{n} & =y_{n}-r U
\end{aligned}
$$

I.e., the flow value of the surplus in the networked state is given by current production minus the flow value of being unemployed (noting that the value of a firm is zero, due to free entry). The flow value of the surplus in the nonnetworked state also reflects the possibility of transiting into the networked state.

These two equations can be combined to yield

$$
(r+\lambda) S_{m}=\tilde{y}-r U
$$

where

$$
\tilde{y}=\tilde{y}(\nu)=y_{m}+\frac{\nu}{r+\lambda+\nu}\left(y_{n}-y_{m}\right)
$$

\footnotetext{
${ }^{2}$ Equation (7) can be seen from the heuristic equation $U \approx b+\exp ^{-r \Delta t}\left(\left(1-\left(\phi+\alpha_{w}\right) \Delta t\right) U+\phi \Delta t \int_{\kappa} \max \{U, \bar{U}-\kappa\} d F(\kappa)+\left(\alpha_{w} \Delta t\right) \theta S_{m}\right)$ as $\Delta t \rightarrow 0$.
} 
is an average of the labor productivities ${ }^{3}$. A higher rate of joining a network increases ceteris paribus the surplus in the same way that a higher productivity would.

The vacancy posting condition is given per

$$
k=\alpha_{e}(1-\theta) S_{m}
$$

As in equation (43) of Rogerson, Shimer and Wright (2005), it follows that the matching rates $\alpha_{e}$ and $\alpha_{w}$ satisfy

$$
\frac{r+\lambda+\alpha_{w} \theta}{(1-\theta) \alpha_{e}}=\frac{\tilde{y}-\tilde{b}}{k}
$$

This equation amounts to a fixed point problem. Given a "guess" for the cut-off value $\kappa^{*}$, calculate $\chi\left(\kappa^{*}\right)$. Under standard conditions on the matching function, the left-hand side has a unique solution for the matching rates $\alpha_{w}=\alpha_{w}(v / u)$ and $\alpha_{e}=\alpha_{e}(v / u)$ and the ratio of vacancies to unemployment $v / u$. Given values for $\alpha_{e}$ and $\alpha_{w}$, calculate $S_{m}$ and $U$ per (10) and (8), and calculate a new value for $\kappa^{*}=\bar{U}-U$. This new value has to be consistent with the initial "guess" in order for this to be a valid fixed point. Given that there is a unique solution, if $\phi=0$, a standard perturbation argument then shows that there is a unique fixed point as a continuous function of $\phi$ for $\phi$ near zero.

Equation (11) provides a number of key insights into this model. The averaged labor productivity $\tilde{y}$ and the "modified" unemployment benefit $\tilde{b}=$

\footnotetext{
${ }^{3}$ This averaged labor productivity $\tilde{y}$ is generally slightly different from the population average labor productivity, which is given by

$$
y^{a}=y_{m}+\frac{\nu}{\lambda-\phi F\left(\kappa^{*}\right)+\nu}\left(y_{n}-y_{m}\right)
$$
}


$b-\phi \chi\left(\kappa^{*}\right)$ play the same role as in the standard model, and provide the channel for the networking and migration effects here. A lower networking rate $\nu$ and a larger migration rate $\phi \chi\left(\kappa^{*}\right)$ both have the effect of discouraging job creation, decreasing the job matching rate $\alpha_{w}$ for workers, increasing the vacancy filling rate $\alpha_{e}$ for firms and thus increasing the surplus of a nonnetworked match $S_{m}$ according to equation (10). A lower job matching rate $\alpha_{w}$ decreases the value of being unemployed $U$ and consequently increases the migration treshold $\kappa^{*}$, i.e. makes emigration more likely.

For the dynamics of the population of workers, let $u_{t}$ be the mass of unemployed workers, and recall that $m_{t}$ is the mass of workers in a nonnetworked match and $n_{t}$ the mass of workers in networked matches. The evolution of these masses is given by the differential equations ${ }^{4}$

$$
\begin{aligned}
\dot{u}_{t} & =-\left(\phi F\left(\kappa_{t}^{*}\right)+\alpha_{w, t}\right) u_{t}+\lambda\left(m_{t}+n_{t}\right) \\
\dot{m}_{t} & =\alpha_{w, t} u_{t}-(\nu+\lambda) m_{t} \\
\dot{n}_{t} & =\nu m_{t}-\lambda n_{t}
\end{aligned}
$$

(where it may be good to recall that immigration has been assumed or approximated to be zero). Generally, there will be migration out of the region, and therefore, $u_{t}, m_{t}$ and $n_{t}$ will not have a constant steady state. Let

$$
\pi_{t}=u_{t}+m_{t}+n_{t}
$$

\footnotetext{
${ }^{4}$ I implicitely assume that only unemployed workers find it beneficial to move, if they draw a low value for the moving cost. Other interesting possibilites are not analyzed here. For example, if the discrepancy between the two regions is large enough, the value of having work $U+\theta S_{m}$ or even $U+\theta S_{n}$ for networked firms in the region under consideration may be lower than the value $\bar{U}$ of being unemployed in the destination region. In that case, agents drawing a sufficiently low moving cost will quit their current job and move. This additional reason for job separation would give rise to modifications of the surplus calculations above.
} 
be the total population in the region. Define

$$
\tilde{u}_{t}=\frac{u_{t}}{\pi_{t}}, \quad \tilde{m}_{t}=\frac{m_{t}}{\pi_{t}}, \quad \tilde{n}_{t}=\frac{n_{t}}{\pi_{t}}
$$

as the shares of the total population of workers for each of the three possibilities. I shall concentrate on the case where these shares are constant. Note that the rate of population decrease is given by

$$
\frac{\dot{\pi}_{t}}{\pi_{t}}=-\phi F\left(\kappa_{t}^{*}\right) \tilde{u}_{t}
$$

With a constant share of unemployed $\tilde{u}_{t} \equiv \tilde{u}$, the population decreases exponentially.

Let $\hat{u}_{t}$ be the relative change of $\tilde{u}_{t}$, i.e., the time derivative of $\tilde{u}_{t}$ divided by $\tilde{u}_{t}$. Define $\hat{m}_{t}$ and $\hat{n}_{t}$ likewise. Exploiting e.g. $\hat{u}_{t}=\dot{u}_{t} / u_{t}-\dot{\pi}_{t} / \pi_{t}$ and imposing $\hat{u}_{t} \equiv 0, \hat{m}_{t} \equiv 0$ and $\hat{n}_{t} \equiv 0$ yields

$$
\begin{aligned}
\tilde{u} \alpha_{w} & =(1-\tilde{u})\left(\lambda-\phi F\left(\kappa^{*}\right) \tilde{u}\right) \\
\nu \tilde{m} & =\left(\lambda-\phi F\left(\kappa^{*}\right) \tilde{u}\right) \tilde{n} \\
1 & =\tilde{u}+\tilde{m}+\tilde{n}
\end{aligned}
$$

Given the solution for $\kappa^{*}$ and $\alpha_{w}$, the first equation is a quadratic equation for $\tilde{u}$, with the relevant of the two solutions coinciding with the standard solution

$$
\tilde{u} \rightarrow \frac{\lambda}{\lambda+\alpha_{w}}
$$

as $\phi \rightarrow 0$. Given $\tilde{u}$, the remaining two linear equations can now be solved for $\tilde{m}$ and $\tilde{n}$.

With equation (11) and for $\phi$ sufficiently low, a lower networking rate $\nu$ results in a lower job finding rate $\alpha_{w}$ and a higher emigration rate $\phi F\left(\kappa^{*}\right)$. Equation (16) furthermore shows that the share of unemployed is also higher. 
Both, the higher unemployment share $\tilde{u}$ as well as the faster emigration rate result in a faster rate of population decrease, see equation (12).

So far, I have not determined the networking rate $\nu$. A solution to the equations above exists both for $\nu=\nu_{h}$ and $\nu=\nu_{l}$. Equation (14) then shows, that the equilibrium ratio of $m_{t}$ to $n_{t}$ is given by imposing $\hat{n}_{t}=0$ in the equation

$$
\hat{n}_{t}=\nu \frac{m_{t}}{n_{t}}-\left(\lambda-\phi F\left(\kappa^{*}\right) \tilde{u}\right)
$$

With (6), the calculated equilibrium is consistent with the step function assumed above for $\nu=\nu\left(m_{t} / n_{t}\right)$, provided $\phi$ or $F\left(\kappa^{*}\right)$ is sufficiently small.

A graphical representation of equation (17) is provided in figure 14. There are two equilibria relevant for our discussion. The "highly networked" equilibrium is the equilibrium, in which $\nu=\nu_{h}$, unemployment is low, and average labor productivity $\tilde{y}(\nu)$ is high. In a full general equilibrium, this equilibrium ought to characterize the destination region ("West Germany", "vibrant city", "industrial core") for migrants, thus fixing $\bar{U}$. In that region, there is no outward migration. Ignoring inward migration, the equilibrium is given by the point $W$ in figure 14. The "weakly networked equilibrium", given by point $E$ in figure 14, is the network with $\nu=\nu_{l}$, high unemployment and persistent emigration. One may want to think of this equilibrium as characterizing "East Germany" or, generally, a dying region. Emigration in this model never stops, eventually turning a dying region into a wasteland. The two equilibria balance two offsetting forces. The relatively higher unemployment in equilibrium $\mathrm{E}$ attracts more vacancy creation than in equilibrium W. However, the surplus from production is lower in the E equilibrium, due to the lower networking rate, discouraging vacancy creation.

The two other solutions to (17), shown as points A and B in figure 14, require additional differences between the two regions. At point $A$, emigra- 
tion persists despite a high networking rate. At point $B$, no emigration takes place despite a low networking rate. While point $\mathrm{B}$ can be understood as the equilibrium in an economy without the possibility of emigration to a more vibrant economy (or with prohibitively high moving costs for all), point A requires that the destination region remains more attractive, even if the rate of networking in both regions is equal.

Interestingly, for large enough values of $\phi$, the equilibrium $\mathrm{E}$ disappears. Essentially, if emigration is fast, new matches come on line rarely, and existing matches are relatively long lived. As a result, networked matches dominate more than they would in the absence of migration. Whether this feature should be regarded as a somewhat artificial property of this model or a valid prediction requires further research ${ }^{5}$. The flip-side to this argument is that the highly networked equilibrium $W$ may also disappear with a high rate of immigration (which we have ignored in the analysis above), as this triggers the creation of many new non-networked firm-worker pairs, overloading the capacity of existing networks to integrate new members. The slump in West Germany likely has many causes, but absorbing and integrating a new workforce arriving from East Germany - as this model would then indicate may be one of them.

The emergence and importance of clusters in East Germany has recently been studied and documented in Rosenfeld et al. (2004). In future research, their cluster data should be combined with the migration data of section $\mathrm{B}$ to investigate the implications of the theory here empirically.

The networking externality gives rise to a coordination failure in this model, see e.g. the survey by Cooper (1999). The coordination failure is

\footnotetext{
${ }^{5}$ This feature may be useful for constructing a fully dynamic multi-region version of this model, as it can be utilized to eventually stop the population collapse.
} 
slightly unusual, though, in that it is not a collective failure of firms to decide in favour of networking, but rather a problem of congestion. Given the masses of non-networked and networked firm-worker pairs $m_{t}$ and $n_{t}$, there is nothing that can be done further, as the networking rate is assumed to be exogenous. If there is a coordination failure in this model, then it occurs earlier: given a certain number of networked firms $n_{t}$, a lower rate of entry (and thus higher unemployment!) would result in a higher ratio of networked to nonnetworked firms and would trigger the switch to a higher networking rate $\nu_{h}$. One solution would be to tax entry of firms in an already depressed region in order to give existing but small networks a chance to grow at a healthy pace, thereby giving the existing unmatched firms a better chance to join. This is likely stretching the implications of this model too far, though. Rather, a more detailed modelling of the networking process should be attempted before embarking on policy recommendations. Structural policies, which aim at providing fertile grounds for networks of firms, or which encourage entry of key firms, around which networks can crystalize, then seem likely candidates for yielding beneficial results.

But skepticism is in order. In his Wall Street Journal op-ed piece on German reunification, Robert Barro (1991) wrote: "No doubt, the slowness of the adjustment and the substantial movement of persons will create pressures for the German government to speed up the process. There is, however little in the history of regional growth in the U.S. and Western Europe to suggest that governments can accelerate convergence... . The forces of convergence are powerful in the long run, but anything approaching parity between eastern and western Germany is unimaginable anytime soon.". Nearly 15 years later and given the massive fiscal transfers from West to East Germany, these insights may - unfortunately - still be correct. 


\section{References}

[1] Barro, Robert J. (1991, May 3rd), "Eastern Germany's long haul," in The Wall Street Journal, Dow Jones and Company.

[2] Barro, Robert J. and Xavier X. Sala-i-Martin (1995), Economic Growth, New York: McGraw-Hill.

[3] Barro, Robert J. (1996), Getting it right, MIT Press.

[4] Barro, Robert J. (2002), Nothing is Sacred, MIT Press.

[5] Busch, Ulrich (2002), "Am Tropf - Die Ostdeutsche Transfergesellschaft," trafo verlag, Berlin.

[6] Burda, Michael (2006), "What kind of shock was it? Regional integration of Eastern Germany after unification," American Economic Review, Papers and Proceedings, this issue.

[7] Canova, Fabio Canova and Morten Ravn (2000), "The Macroeconomic Effects of German Unification: Real Adjustments and the Welfare State," Review of Economic Dynamics, Academic Press for the Society for Economic Dynamics, vol. 3(3), pages 423-460.

[8] Cooper, Russell W. (1999), Coordination Games, Cambridge University Press, Cambridge, UK.

[9] Fuchs-Schündeln, Nicola and Izem, Rima (2006), "What Causes the Low Labor Productivity in East Germany? A Spatial Analysis.", draft, Harvard University. 
[10] Fuchs-Schündeln, Nicola and Schündeln, Matthias, (2005), "Precautionary Savings and Self-Selection - Evidence from the German Reunification "Experiment" ", Quarterly Journal of Economics, 120(3), 1085-1120.

[11] Gabaix, Xavier and Yannis Ioannides, "The Evolution of City Size Distributions," in Handbook of Regional and Urban Economics, vol. 4, Vernon Henderson and Jacques-Francois Thisse, eds., Chapter 53 (Oxford: Elsevier Science, 2004), 2341-2378.

[12] Fujita, Masahisa, Paul Krugman and Anthony J. Venables (1999), The Spatial Economy: Cities, Regions and International Trade. MIT Press.

[13] Hunt, Jennifer (2006), "Staunching Emigration from East Germany: Age and the Determinants of Migration," Journal of the European Economic Association, forthcoming.

[14] Kremer, Michael (1993), "The O-Ring Theory of Economic Development," Quarterly Journal of Economics, August, pp. 551-576.

[15] Krugman, Paul R., (1996), The Self-Organizing Economy, Blackwell Publishers Ltd, Oxford, UK.

[16] Rogerson, Richard, Robert Shimer and Randall Wright (2005), "SearchTheoretic Models of the Lsbor Market: a survey," draft, University of Pennsylvania.

[17] Rosenfeld, Martin T.W., Peter Franz, Jutta Günther, Gerhard Heimpold, Rupert Kawka, Franz Kronthaler, Michael Barkholz (October 2004), Innovative Kompetenzfelder, Produktionsnetzwerke und Branchenschwerpunkte der ostdeutschen Wirtschaft. Endbericht, a study at the Institute für Wirtschaftsforschung Halle, IWH. 
[18] Sinn, Gerlinde and Sinn, Hans-Werner (1993), Kaltstart. Volkswirtschaftliche Aspekte der deutschen Vereinigung., 3rd edition, Munich 1993.

[19] Sinn, Hans-Werner (2002), "Germany's Economic Unification: An Assessment after Ten Years," Review of International Economics, 10(1), 113-128.

[20] Snower, Dennis J. and Merkl, Christian (2006), "The Caring Hand that Cripples: The East German Labor Market after Reunification," American Economic Review, Papers and Proceedings, this issue.

[21] Spence, Michael (1973), "Job Market Signaling," Quarterly Journal of Economics 83, 355-372.

\section{Figures}




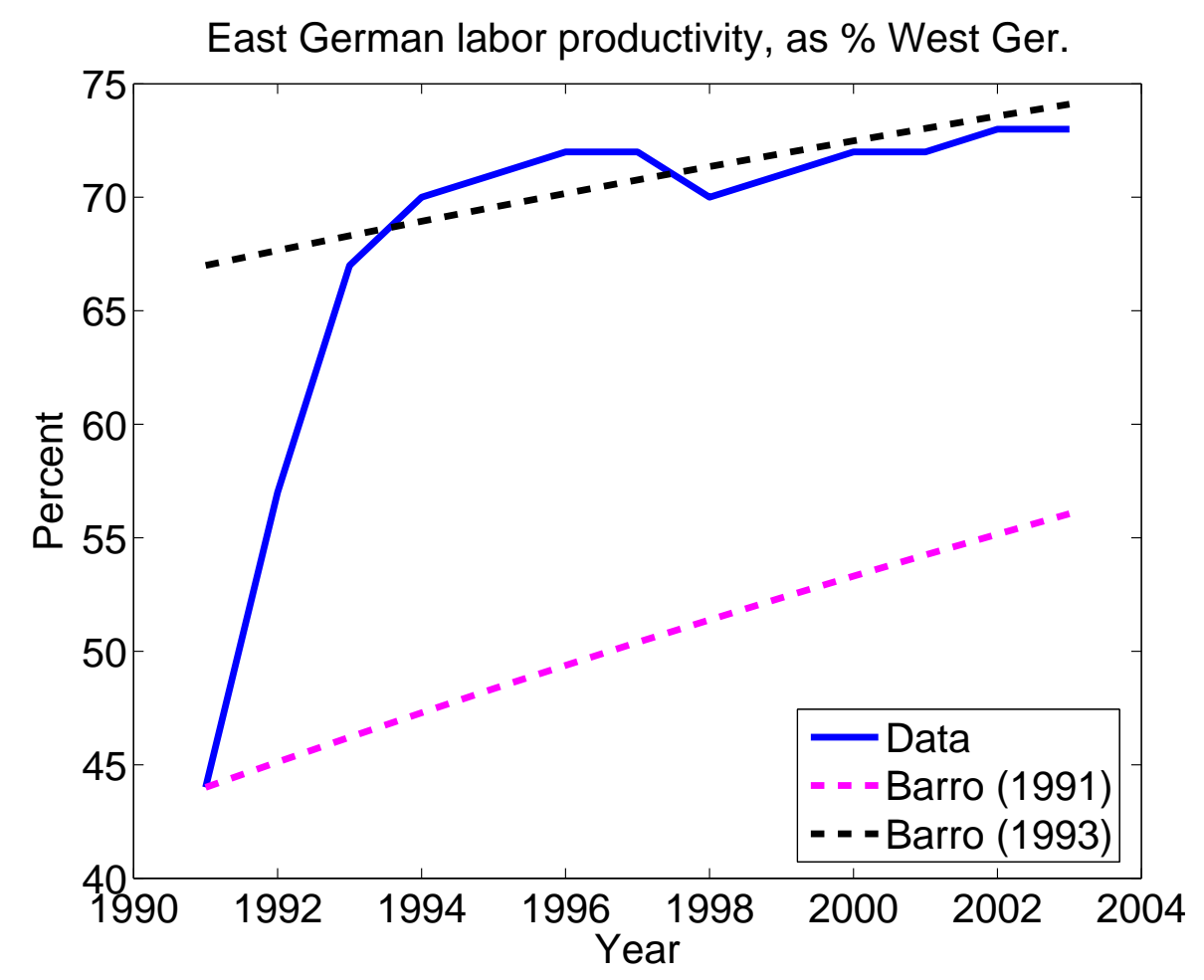

Figure 2: Productivity convergence, compared to the $2 \%$ convergence prediction of Barro. Productivity convergence appears to have been fast from 1991 to 1993, so the prediction based on the 1991 numbers is far from the facts. Applying the prediction on the basis of the numbers for 1993, however, works surprisingly well. The data is from Burda (2006). 


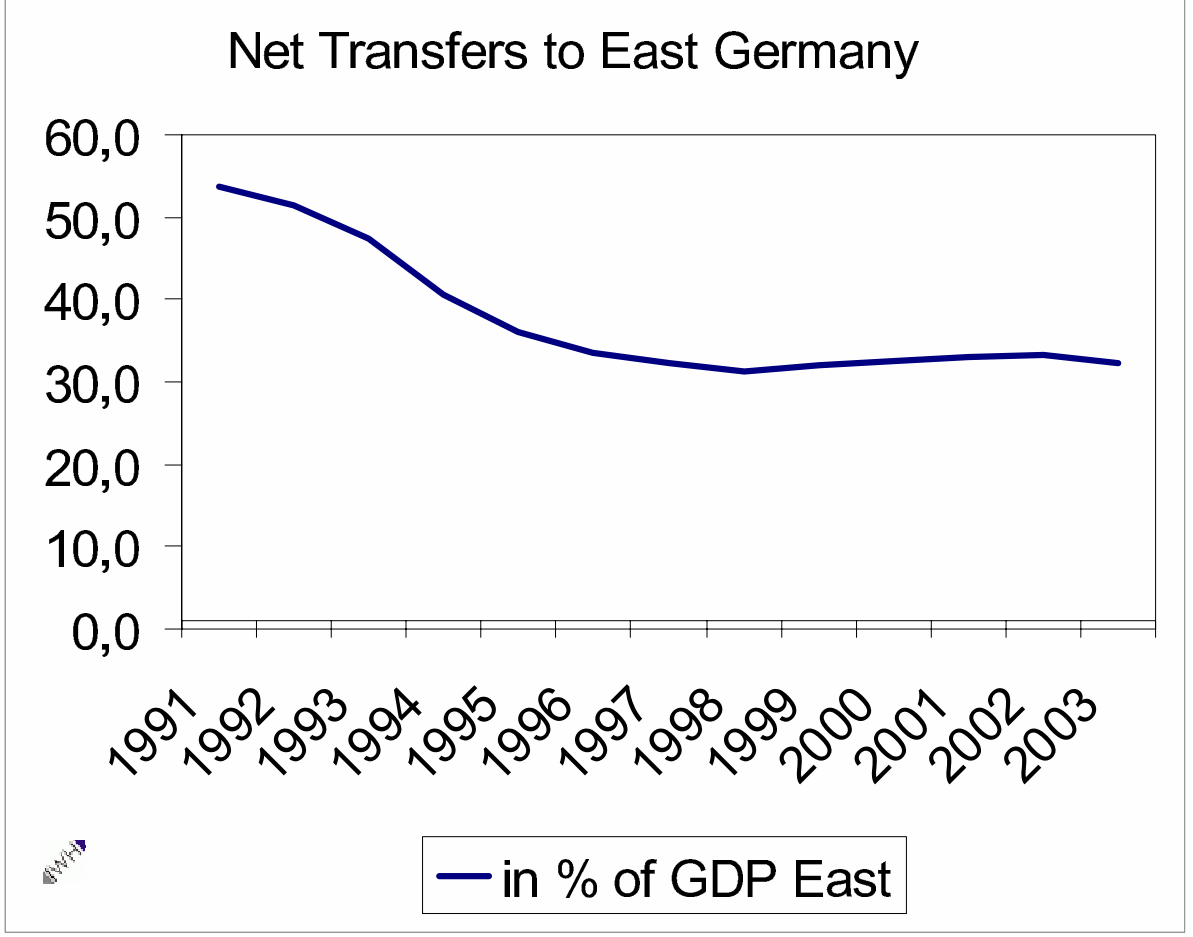

Figure 3: Fiscal Transfers from West to East Germany. 
Migration from East to West Germany

(in \% Population East Germany with Berlin, 2004)

$\rightarrow-$ From East $-\square-$ To East $-\bullet-$ Net

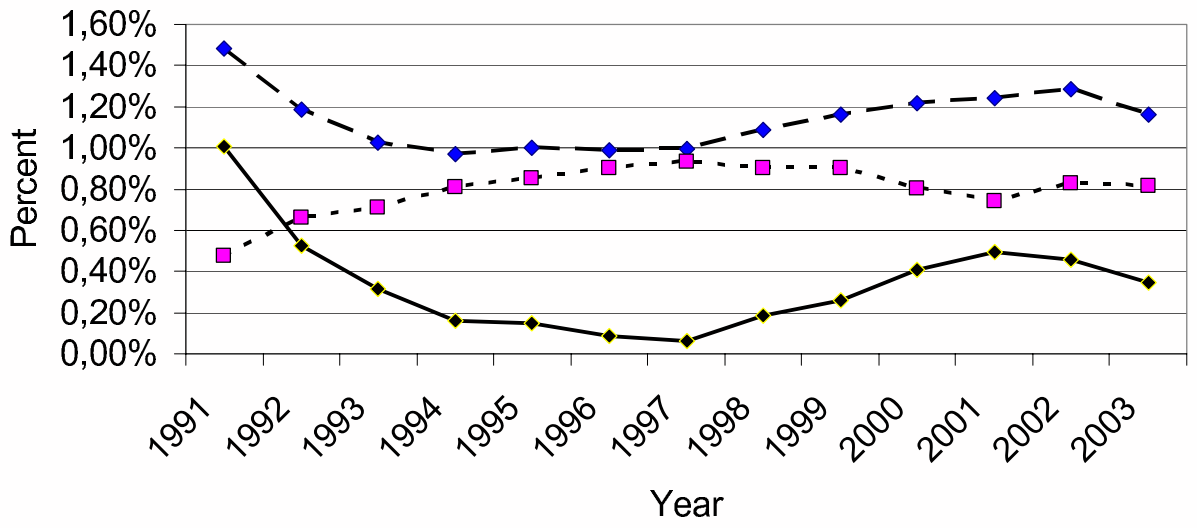

Figure 4: Migration Pattern for Germany. 


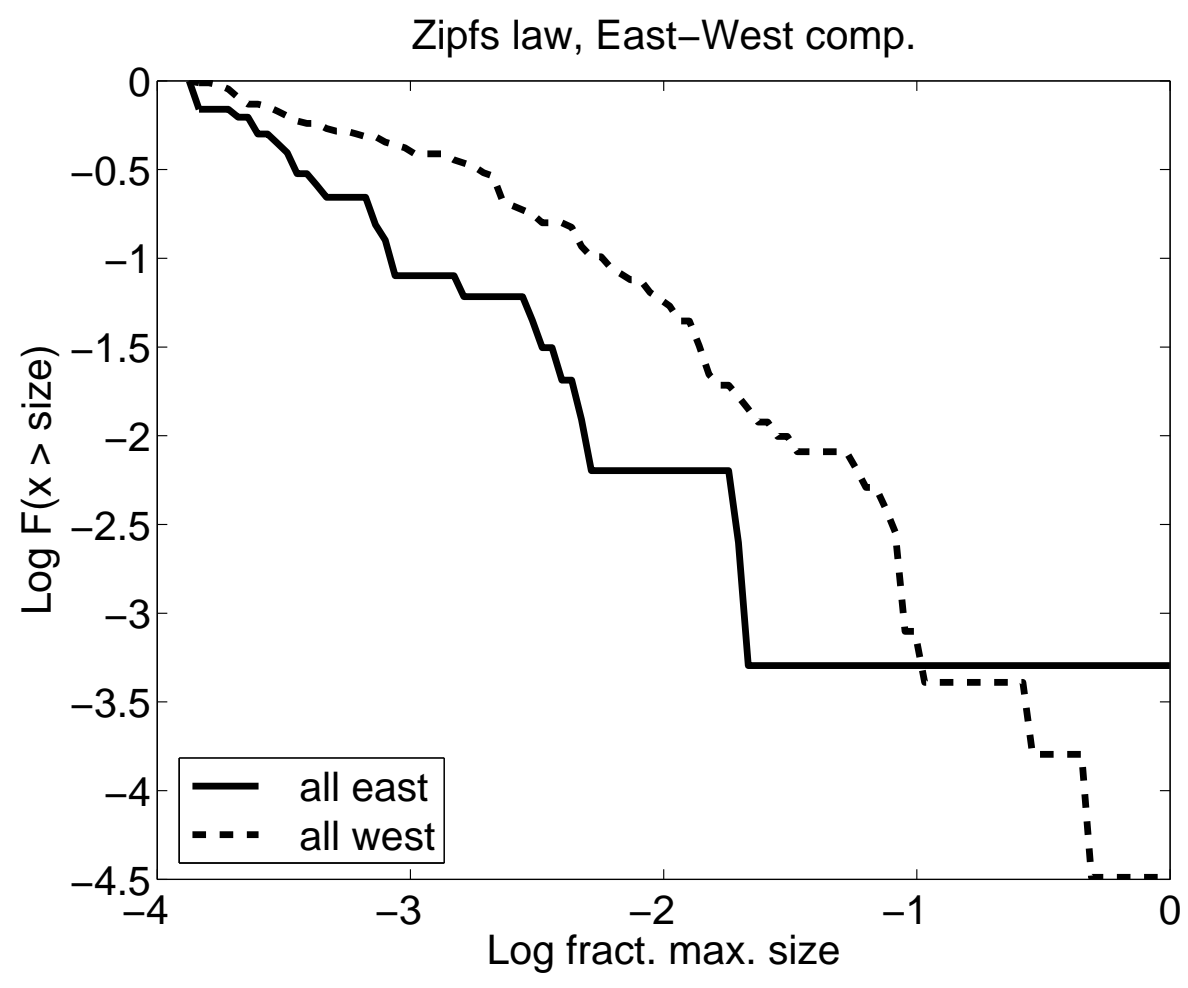

Figure 5: Comparing the distribution of city sizes in East and West Germany. 


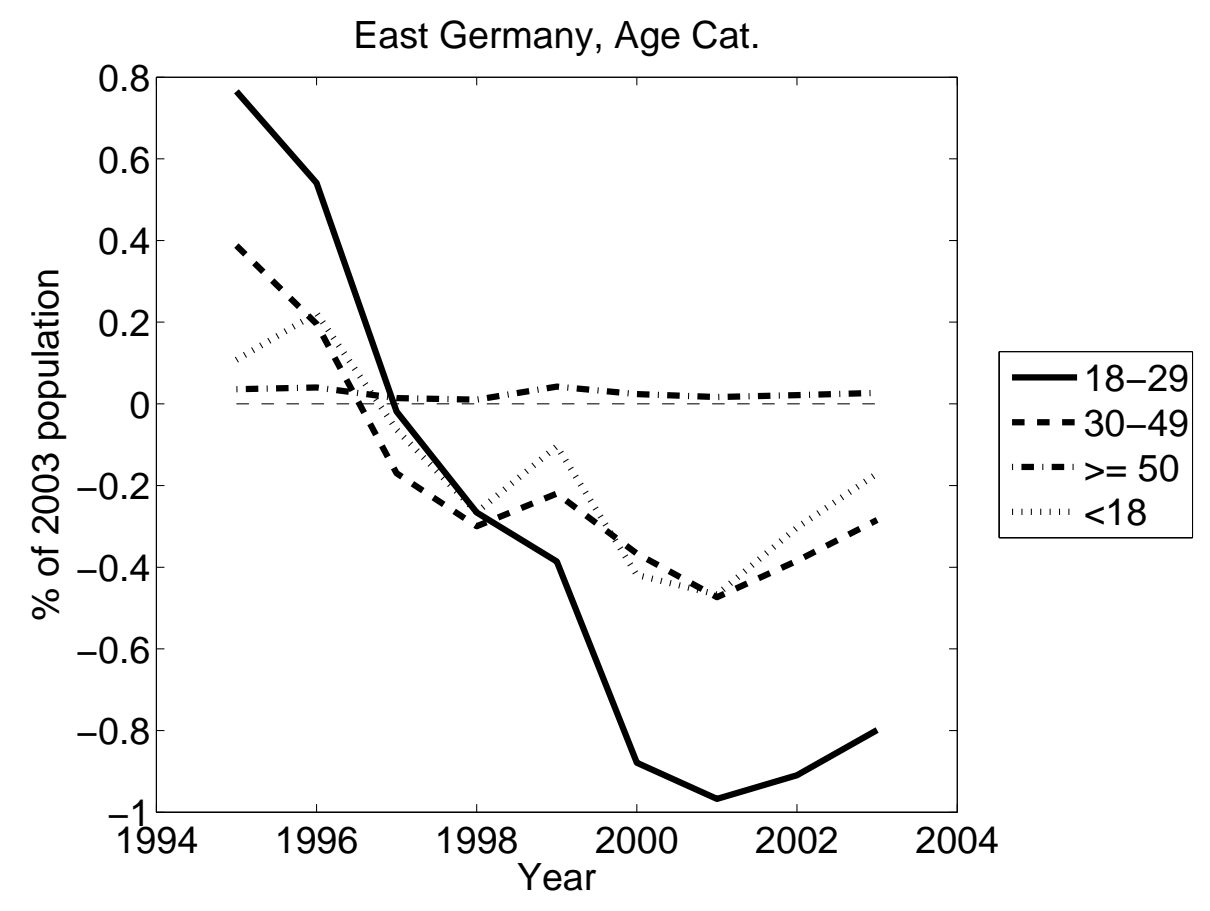

Figure 6: Net migration rates for various age groups, East Germany. Only people above age 50 stay in East Germany, all others gradually leave. 


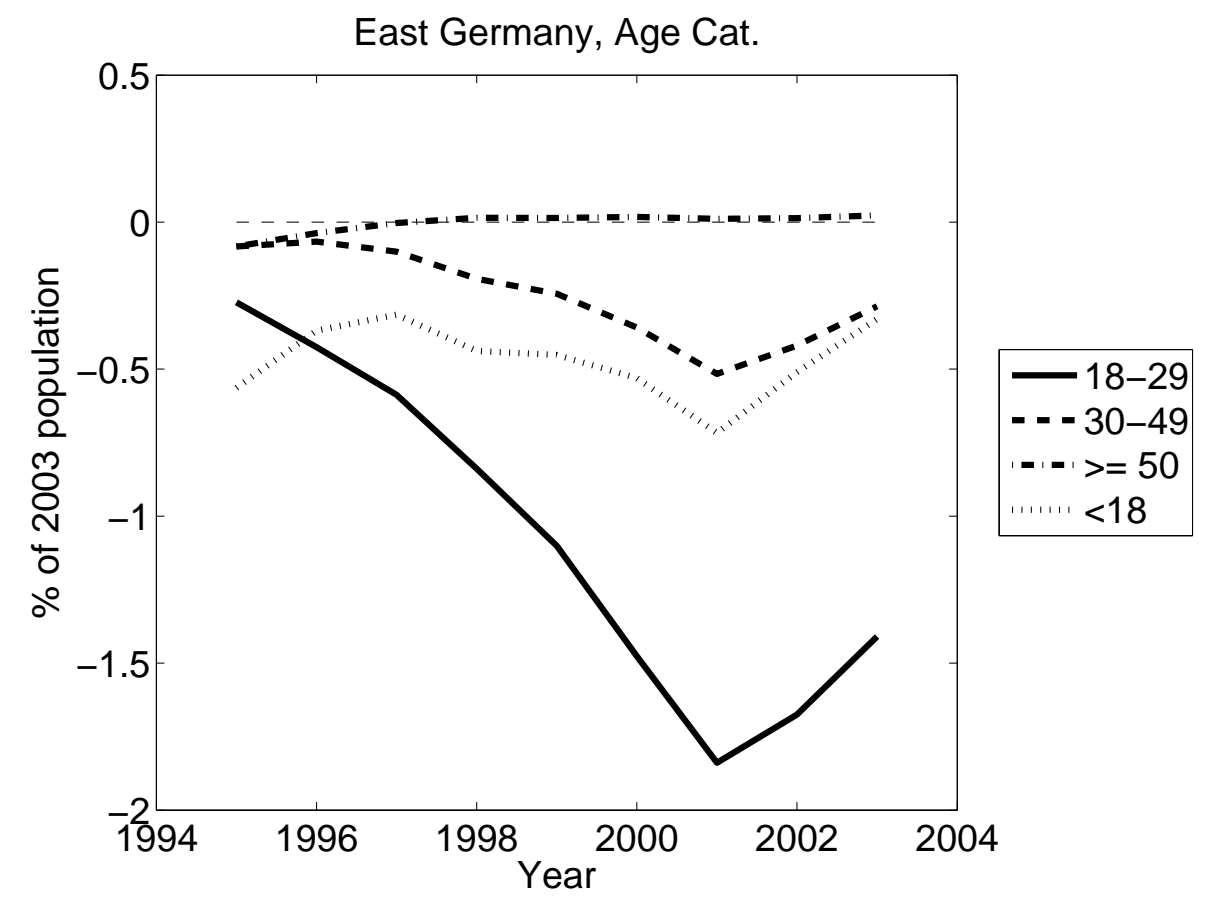

Figure 7: Net migration rates for various age groups, East Germany, calculated for inner-German migrants, i.e., excluding migration crossing the German border. 


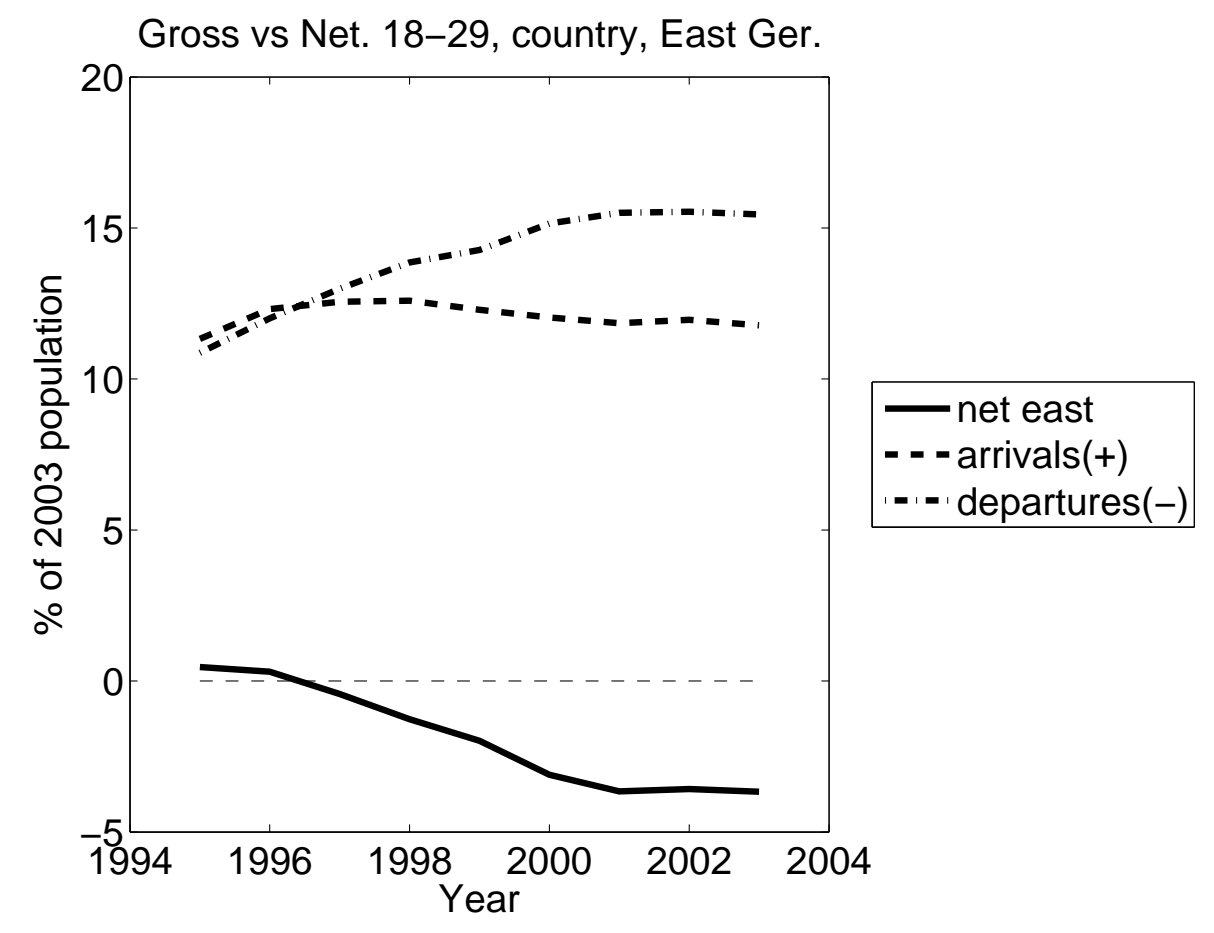

Figure 8: Gross and net migration of people, aged 18-29, into East Germany, in percent of the 2003 population of that age group. 


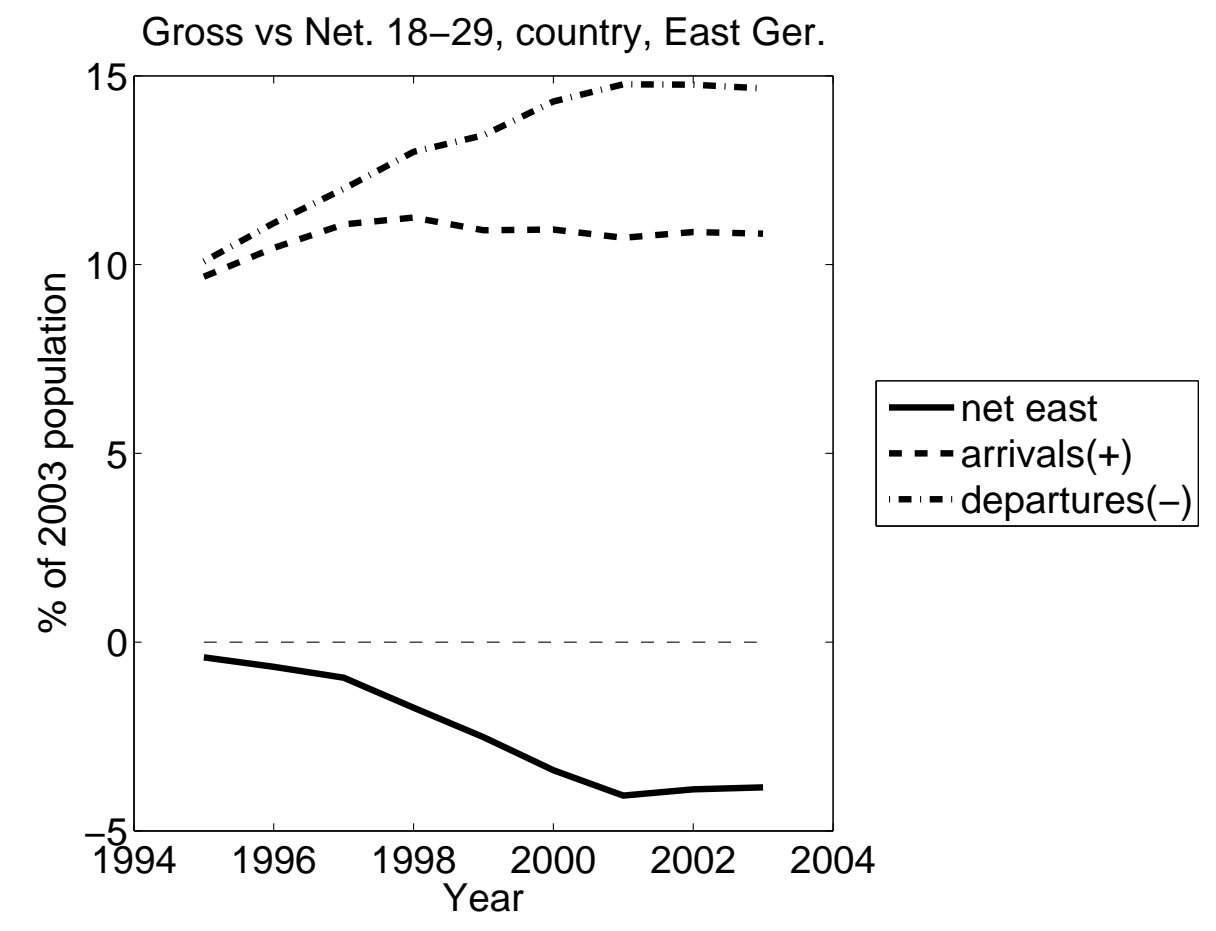

Figure 9: Gross and net migration of people, aged 18-29, into East Germany, in percent of the 2003 population of that age group. Here, only inner-German migration is shown. 


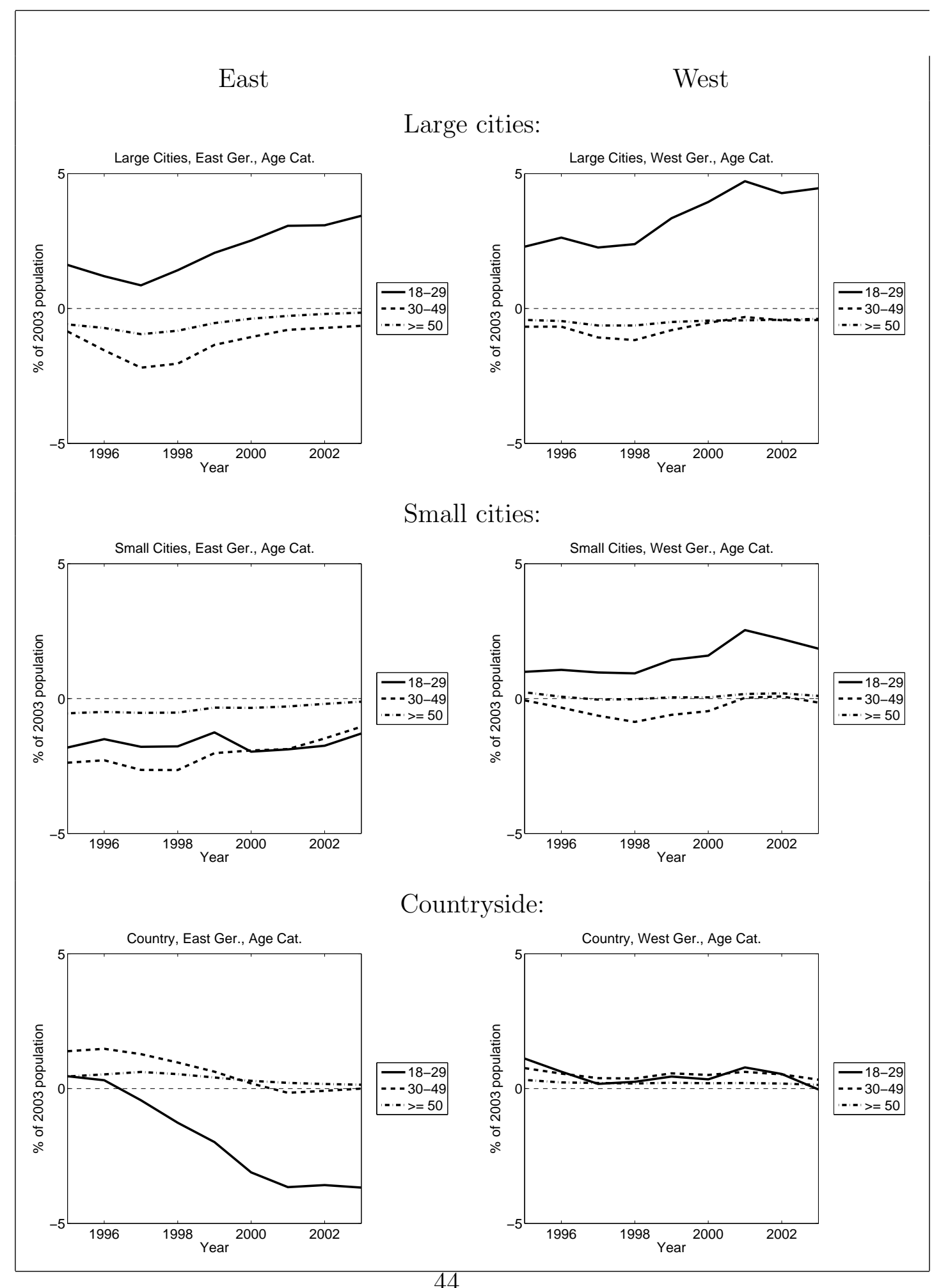

Figure 10: Net migration rates for various age groups and regions, comparing

East and West Germany. 


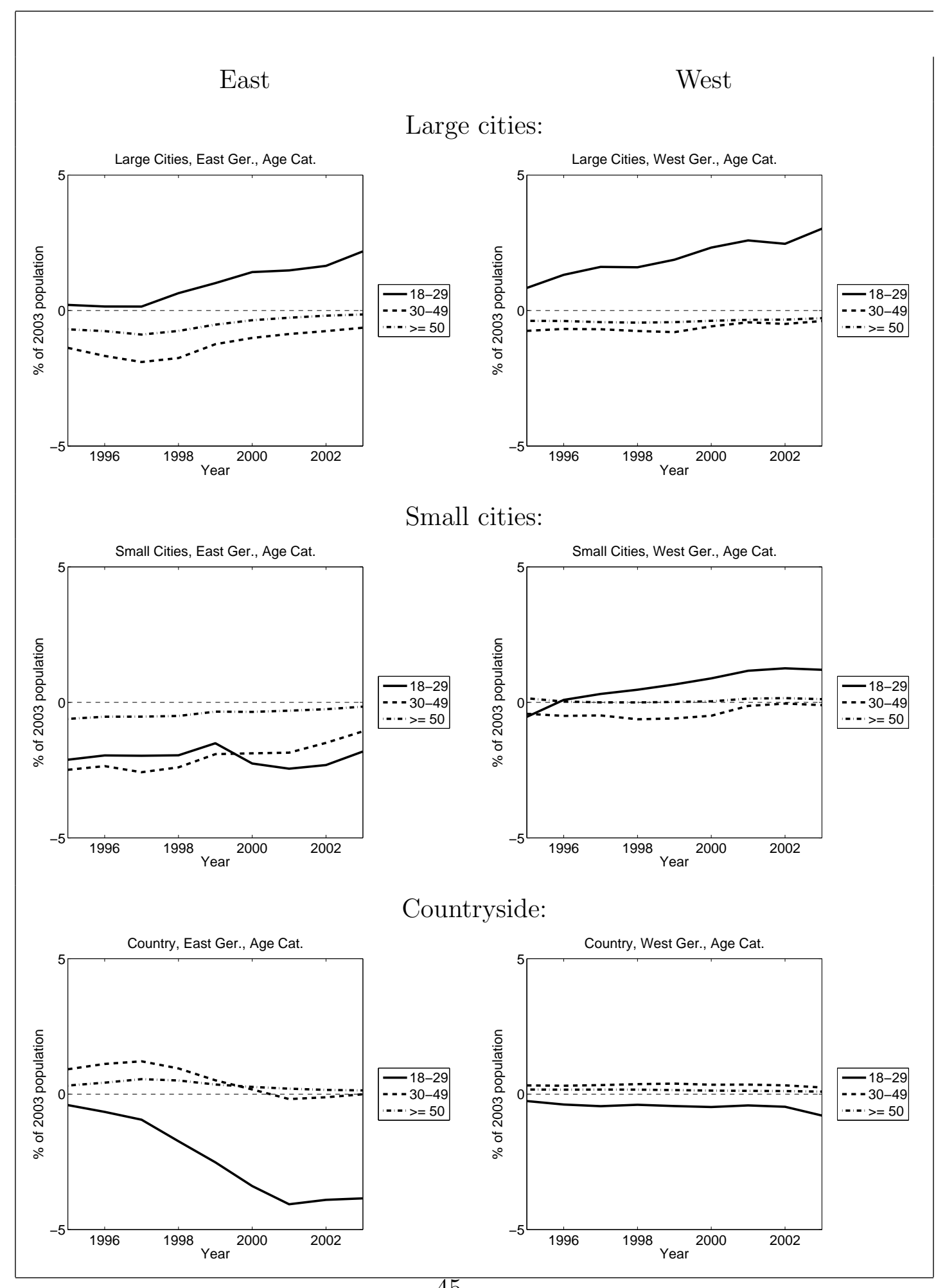

45

Figure 11: Net migration rates for various age groups and regions, comparing

East and West Germany, inner-German migration only. 


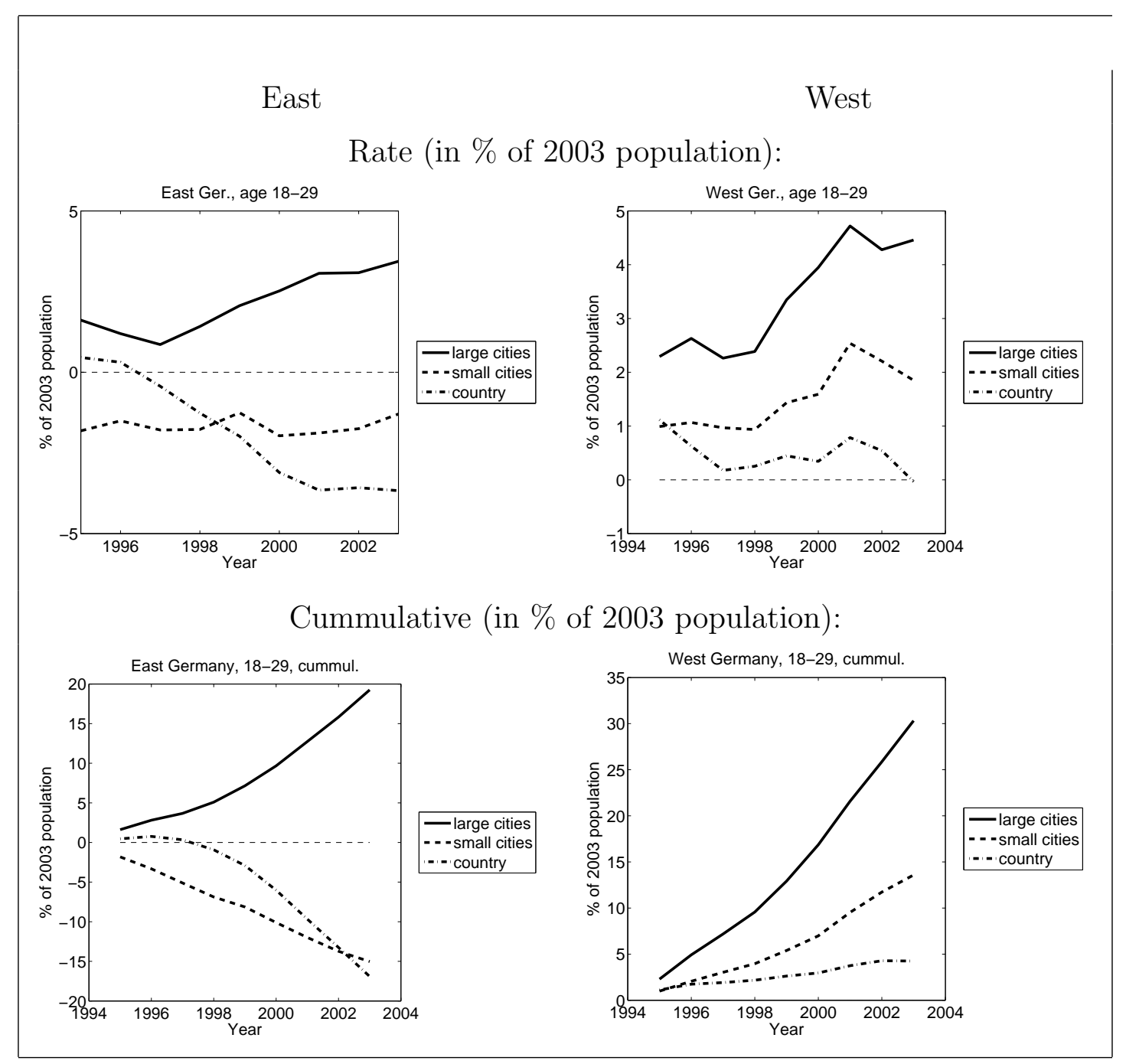

Figure 12: Migration patterns of 18-29 year olds. 


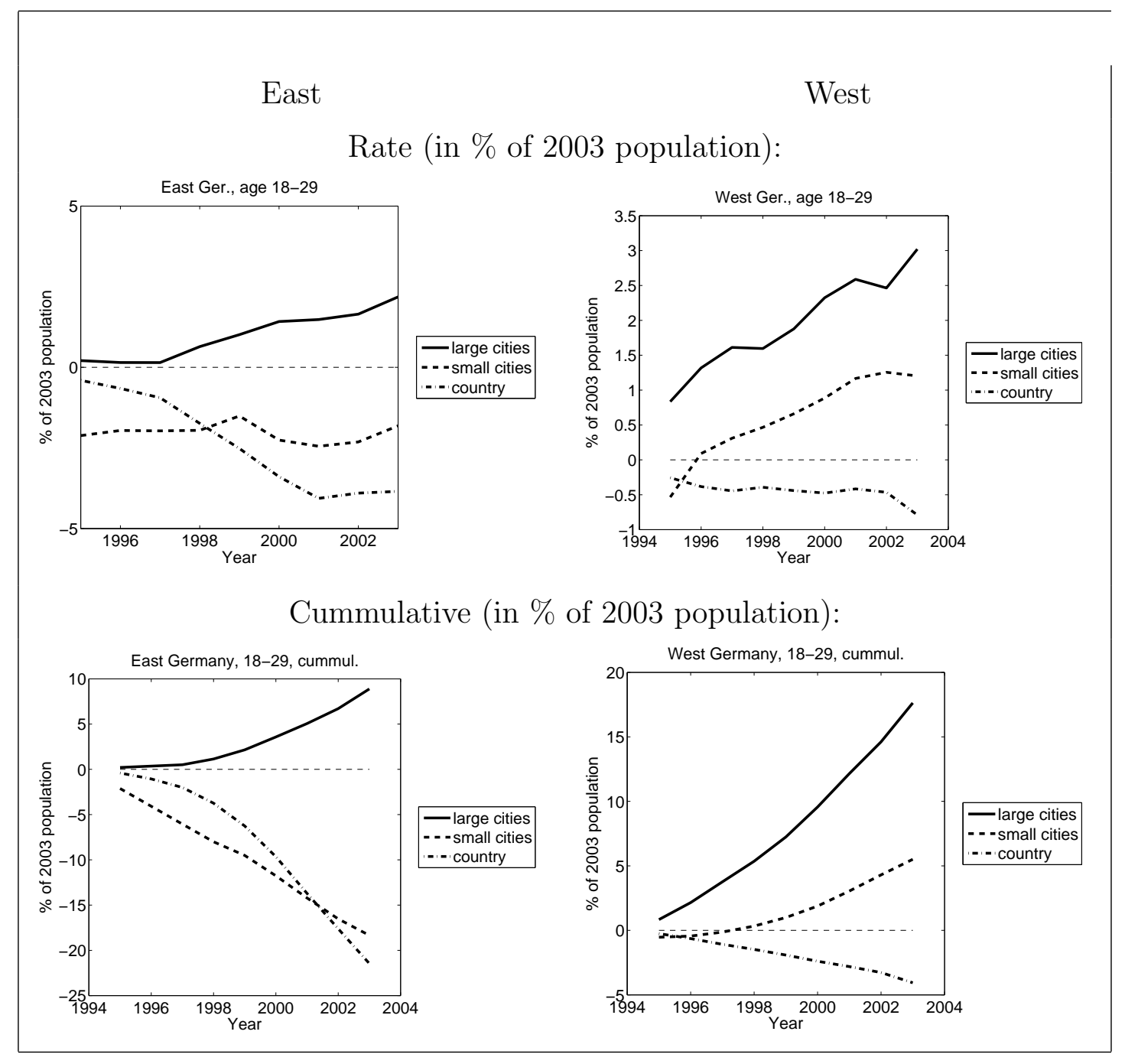

Figure 13: Migration patterns of 18-29 year olds, inner-German migration only. 


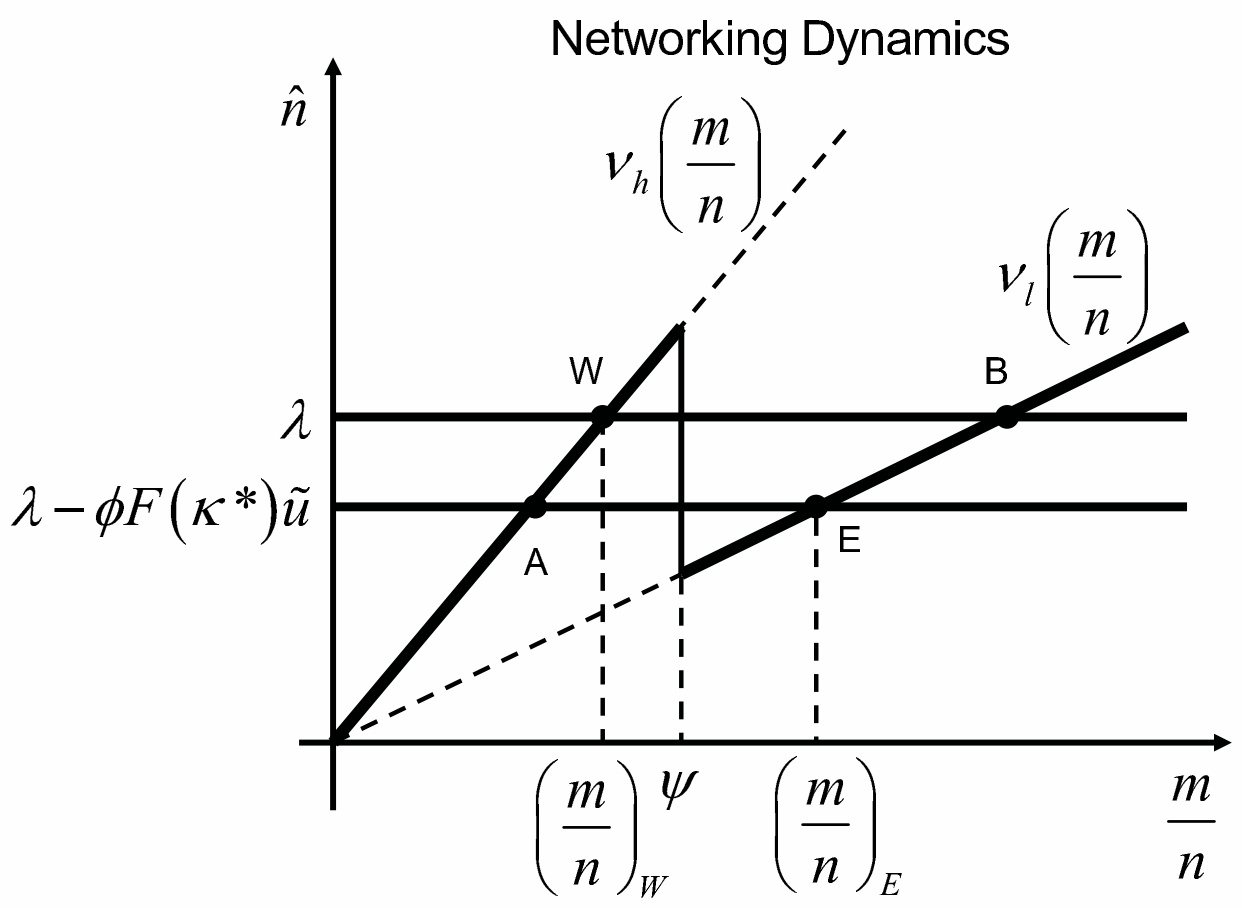

Figure 14: A Graphical Representation of the Dynamics for the fraction $\tilde{n}$ of networked firm-worker pairs as a function of the ratio of non-networked to networked firm-worker pairs, $m / n$. The equilibrium E ("East Germany") exhibits low average productivity, high unemployment and persistent emigration, compared to the equilibrium W ("West Germany"). 


\section{SFB 649 Discussion Paper Series 2006}

For a complete list of Discussion Papers published by the SFB 649, please visit http://sfb649.wiwi.hu-berlin.de.

001 "Calibration Risk for Exotic Options" by Kai Detlefsen and Wolfgang K. Härdle, January 2006.

002 "Calibration Design of Implied Volatility Surfaces" by Kai Detlefsen and Wolfgang K. Härdle, January 2006.

003 "On the Appropriateness of Inappropriate VaR Models" by Wolfgang Härdle, Zdeněk Hlávka and Gerhard Stahl, January 2006.

004 "Regional Labor Markets, Network Externalities and Migration: The Case of German Reunification" by Harald Uhlig, January/February 2006. 